University of South Florida

DIGITAL COMMONS

Digital Commons @ University of

@ UNIVERSITY OF SOUTH FLORIDA

South Florida

Marine Science Faculty Publications

College of Marine Science

$4-1-2000$

\title{
Wind-Forced Reversing Jets in the Western Equatorial Pacific
}

Megan F. Cronin

NOAA Pacific Marine Environmental Laboratory

Michael J. McPhaden

NOAA Pacific Marine Environmental Laboratory

Robert H. Weisberg

University of South Florida, weisberg@marine.usf.edu

Follow this and additional works at: https://digitalcommons.usf.edu/msc_facpub

Part of the Marine Biology Commons

\section{Scholar Commons Citation}

Cronin, Megan F.; McPhaden, Michael J.; and Weisberg, Robert H., "Wind-Forced Reversing Jets in the Western Equatorial Pacific" (2000). Marine Science Faculty Publications. 150.

https://digitalcommons.usf.edu/msc_facpub/150

This Article is brought to you for free and open access by the College of Marine Science at Digital Commons @ University of South Florida. It has been accepted for inclusion in Marine Science Faculty Publications by an authorized administrator of Digital Commons @ University of South Florida. For more information, please contact digitalcommons@usf.edu. 


\title{
Wind-Forced Reversing Jets in the Western Equatorial Pacific*
}

\author{
Meghan F. Cronin and Michael J. McPhaden \\ NOAA/Pacific Marine Environmental Laboratory, Seattle, Washington \\ ROBERT H. WEISBERG \\ Department of Marine Science, University of South Florida, St. Petersburg, Florida
}

(Manuscript received 1 October 1998, in final form 9 April 1999)

\begin{abstract}
Upper-ocean zonal currents in the western equatorial Pacific are remarkably variable, changing direction both with time and depth. As a part of the Tropical Ocean and Global Atmosphere Coupled Ocean-Atmosphere Response Experiment, an enhanced monitoring array of moorings measured the upper-ocean velocity, temperature, salinity, and, surface meteorological conditions in the western equatorial Pacific for two years (March 1992-April 1994). Data from this array are used to evaluate the zonal momentum balance. Although nonlinear terms (zonal, meridional, and vertical advection) were at times large, reversing jets were primarily due to an interplay between wind forcing and compensating pressure gradients. In the weakly stratified surface layer, the flow is to a large extent directly forced by local winds. Eastward acceleration associated with westerly wind bursts and westward accelerations associated with easterly trades lead to frequent reversals in the surface-layer flow. However, pressure gradients set up by the wind bursts partially compensate the local wind forcing in the surface layer. Below the surface layer, these pressure gradients tend to accelerate the upper-thermocline flow in a direction opposing the local winds. Consequently, during westerly wind bursts, a reversing jet structure can develop, with a surface eastward current overlying a westward intermediate layer flow, overlaying the eastward Equatorial Undercurrent.
\end{abstract}

\section{Introduction}

Wind forcing has a particularly dramatic ocean response on the equator. With no Coriolis turning, local accelerations can be large, leading to strong currents. However, even for sustained wind forcing, equatorial currents do not accelerate indefinitely. Because of the relatively fast equatorially trapped waves, the equatorial ocean can adjust rapidly to wind forcing by setting up an opposing pressure gradient. The resulting pressure gradient can support a subsurface counterflow, as for example in the case of the eastward Equatorial Undercurrent (EUC) beneath the surface westward South Equatorial Current (SEC) for trade wind forcing. In this paper, we focus on the ocean response to wind forcing in the western equatorial Pacific where frequent reversals in the trade winds associated with westerly wind bursts

* NOAA/Pacific Marine Environmental Laboratory Contribution Number 1912.

Corresponding author address: Dr. Meghan F. Cronin, NOAA/ Pacific Marine Environmental Laboratory, 7600 Sand Point Way NE, Seattle, WA 98115

E-mail: cronin@pmel.noaa.gov
(WWBs) can lead to complex reversing current structures in the upper $300 \mathrm{~m}$.

Reversing currents associated with westerly wind bursts were first observed by Hisard et al. (1970). During a cruise along $170^{\circ} \mathrm{E}$ in March 1967 , trade winds were prevailing and the equatorial currents had a twolayer structure, with a westward $40 \mathrm{~cm} \mathrm{~s}^{-1}$ SEC from the surface to $60 \mathrm{~m}$, and an eastward EUC from $60 \mathrm{~m}$ to $300 \mathrm{~m}$. One month later, the currents had a threelayer structure, with an eastward $20 \mathrm{~cm} \mathrm{~s}^{-1}$ flow in the upper $60 \mathrm{~m}$, westward $40 \mathrm{~cm} \mathrm{~s}^{-1}$ flow between $60 \mathrm{~m}$ and $175 \mathrm{~m}$, and eastward EUC flow between $175 \mathrm{~m}$ and $300 \mathrm{~m}$. In the intervening month between cruises, a WWB had occurred.

Since the Hisard et al. (1970) study, there have been numerous reports of reversing jets in the western equatorial Pacific (e.g., McPhaden et al. 1988, 1990, 1992; Kuroda and McPhaden 1993; Delcroix et al. 1993; Smyth et al. 1996), and even as far east as $170^{\circ} \mathrm{W}$ during El Niños (Weisberg and Hayes 1995; Weisberg and Wang 1997). Due to the lack of data, dynamical analyses of the reversing jet have been incomplete. Using a combination of shipboard, island, and moored time series, McPhaden et al. (1988) showed that during the first several days of the WWB, an eastward "Yoshida jet" (Yoshida 1959) formed with surface acceleration rough- 
ly corresponding to the zonal wind stress forcing. A Kelvin wave generated by the WWB could subsequently be seen propagating eastward across the basin. Thus they hypothesized that the discrepancy between wind stress and surface acceleration after the first few days of the wind burst was due to the pressure gradient variability associated with the Kelvin wave passage. Using hydrographic data from zonal equatorial transects, McPhaden et al. (1990) later observed pressure gradient variability associated with WWBs.

Turbulent mixing is also expected to be important. In particular, McPhaden et al. (1988) apply the Stommel (1960) homogeneous EUC model to the surface layer to explain the development of vertical shear in terms of mixing. Microstructure measurements taken at $2^{\circ} \mathrm{S}$, $156^{\circ} \mathrm{E}$ during a WWB (Smyth et al. 1996) show that turbulent kinetic energy increased during the WWB and, while it was highest in the surface mixed layer, patches of high turbulent kinetic energy were also observed on the upper and lower boundaries of the subsurface westward jet between the surface wind-driven eastward jet and EUC.

Scale analyses suggest that nonlinearities also may be important during strong westerly wind events due to zonal convergence, associated with the Yoshida jet impinging on the unforced region, and meridional Ekman convergence and downwelling; however, advective acceleration has been measured on synoptic timescales only in the central equatorial Pacific (Qiao and Weisberg 1997). There, advective acceleration at any individual depth was found to be comparable in magnitude with the local acceleration, although upon vertical integration across the EUC, the advective acceleration terms tended to cancel.

Unlike the steady trade winds found in the central and eastern tropical Pacific, trade winds in the western equatorial Pacific tend to be weak and punctuated by westerly wind bursts. Harrison and Vecchi (1997) define three westerly wind event composites for the equatorial Pacific, two of which are centered west of the date line $\left(0^{\circ}, 142.5^{\circ} \mathrm{E} ; 0^{\circ}, 170^{\circ} \mathrm{E} ; 2.5^{\circ} \mathrm{S}, 170^{\circ} \mathrm{W}\right)$. The composites had peak wind speeds of 5.5-6.9 $\mathrm{m} \mathrm{s}^{-1}$, fetch 3400 $3800 \mathrm{~km}$, duration 6-7 days, and were either stationary or propagate very slowly westward at $1.3 \mathrm{~m} \mathrm{~s}^{-1}$. Westerly wind bursts in the western equatorial Pacific often occur during the active convective phase of the 30-60 day intraseasonal Madden-Julian oscillation (MJO) (Madden and Julian 1994), which tend to occur more frequently during November through March and during El Niño years. Superclusters of convective clouds associated with MJO have been observed to have an eastward propagation of up to $10-15 \mathrm{~m} \mathrm{~s}^{-1}$ (Nakazawa 1988).

Analytical and numerical models of the ocean response to wind forcing (e.g., Cane and Sarachik 1976; McCreary 1985; Tang and Weisberg 1984; McCreary and Lukas 1986; Weisberg and Tang 1987; Eriksen 1993; Giese and Harrison 1990; Weisberg and Tang
1990; Harrison and Craig 1993; Zhang and Rothstein 1998; Richardson et al. 1999) show that these subtle differences in the WWB characteristics can cause quite different ocean responses. In particular, wind bursts translating at speeds of $10 \mathrm{~m} \mathrm{~s}^{-1}$ predominately excite inertia gravity waves (Erikson 1993), while eastward and westward slowly translating wind bursts tend to excite respectively near-resonant Kelvin or Rossby waves (Weisberg and Tang 1983; Tang and Weisberg 1984; McCreary and Lukas 1986). Recently, Richardson et al. (1999) simulated the formation of a subsurface westward reversing jet by forcing an ocean general circulation model with a stationary WWB. Analysis of the current structure evolution showed that the subsurface westward accelerations were primarily due to the propagation and separation of baroclinic Rossby and Kelvin waves generated at the edges, particularly the eastern edge, of the wind patch.

In this paper, data from the Tropical Ocean Global Atmosphere Coupled Ocean-Atmosphere Response Experiment (TOGA COARE) enhanced monitoring array of Acoustic Doppler Current Profilers (ADCPs) and Tropical Atmosphere Ocean (TAO) thermistor moorings with SEACAT conductivity (salinity) sensors and surface meteorological packages are used to analyze the variability and dynamics of the wind-forced upperocean zonal current structures in the western equatorial Pacific. With this dataset, nearly all terms in the zonal momentum balance can be evaluated for a period of up to two years. Although the basic westward South Equatorial Current overlying the eastward Equatorial Undercurrent is often seen in the data, the vertical structure is highly variable and also exhibits periods with all eastward flow, as well as periods with reversing jets with complex vertical structure. These stacked "ribbons" of flow, sometimes only $50 \mathrm{~m}$ thick, are often coherent over several weeks and over the full zonal extent of our array $(1800 \mathrm{~km})$. Based on observations by Kuroda and McPhaden (1993), these reversing jets can at times be coherent even over ranges of up to a few thousand kilometers. The outline of the paper is as follows: In the next section, data used in the analysis are discussed. In section 3, the methodology is presented. Our main analysis tool is the zonal momentum balance. Results are presented in section 4 and summarized and discussed in section 5 .

\section{Data}

The TAO array consists of nearly 70 Autonomous Temperature Line Acquisition System (ATLAS) moorings in the tropical Pacific and five current meter moorings along the equator. All moorings measure daily averaged wind speed and direction, air temperature, and relative humidity, and surface and subsurface temperature from $1 \mathrm{~m}$ to $500 \mathrm{~m}$ with at least a 1-h sample rate (McPhaden et al. 1998). As a part of TOGA COARE, the TAO array was enhanced with additional moorings 


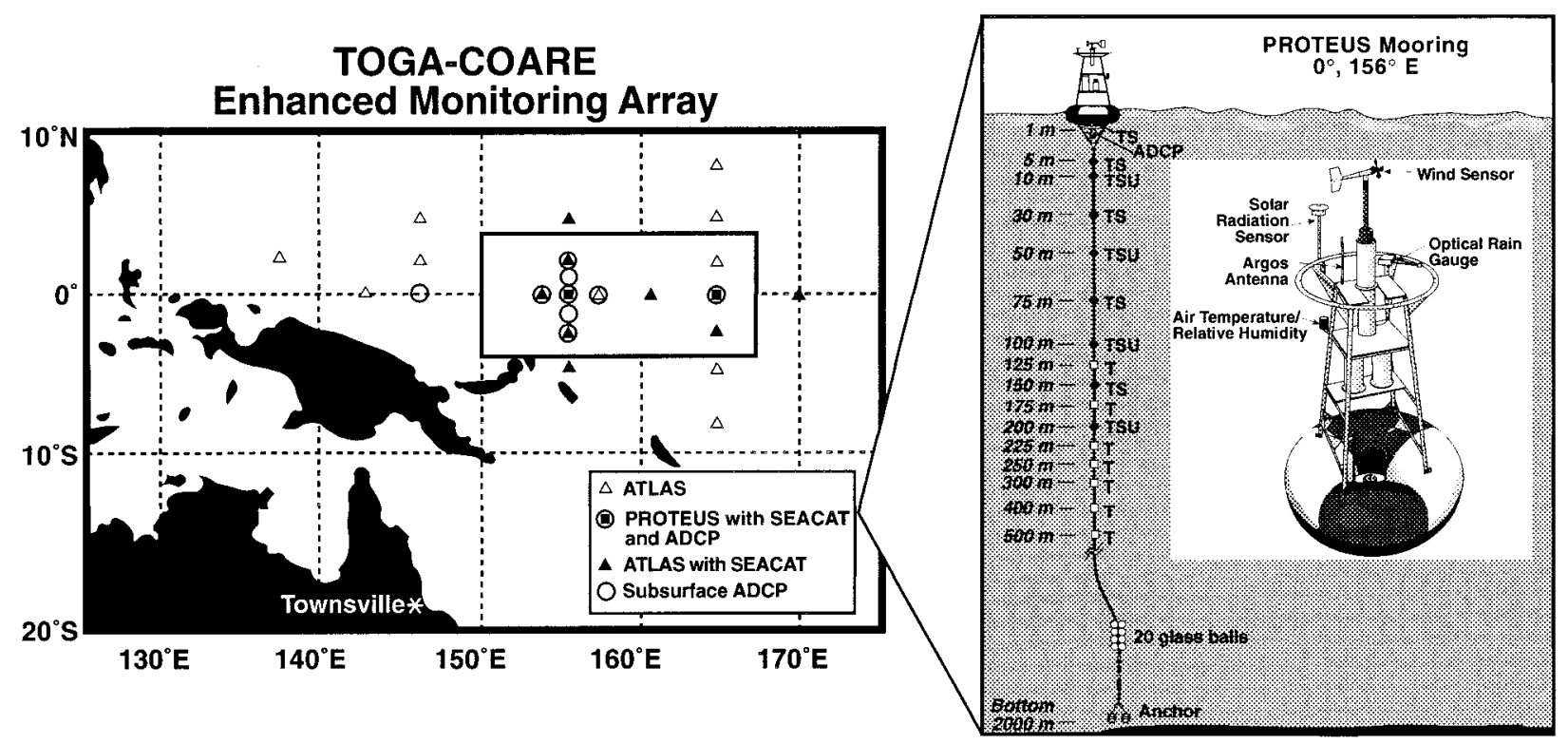

FIG. 1. The COARE Enhanced Monitoring Array (EMA). The array included moored ADCPs, Tropical Atmosphere Ocean (TAO) ATLAS moorings, some of which were enhanced with SEACAT temperature and conductivity sensors, and TAO PROTEUS moorings enhanced with SEACAT sensors. The $0^{\circ}, 156^{\circ} \mathrm{E}$ PROTEUS mooring is shown in the inset.

and instrumentation to monitor upper-ocean currents, salinity, and temperature (with higher spatial and temporal resolution) along the equator and the $156^{\circ} \mathrm{E}$ meridian for approximately two years (March 1992-April 1994). The enhanced monitoring array (EMA) is shown in Fig. 1, and schematic diagrams of the data availability are shown in Fig. 2. At the $0^{\circ}, 156^{\circ} \mathrm{E}$ central site, nearly all terms in the zonal momentum balance could be evaluated. These data and the surface meteorological data used in the analysis are described below.

\section{a. Currents}

Upper-ocean currents in the EMA region were measured at five sites along the equator and four sites off the equator along the $156^{\circ} \mathrm{E}$ meridian (Figs. 1, 2, Table $1)$ by an array of $153.6-\mathrm{kHz}$ ADCPs. Two sites, $0^{\circ}$, $165^{\circ} \mathrm{E}$ and $0^{\circ}, 156^{\circ} \mathrm{E}$ (from August 1991 to March 1993), had Profile Telemetry of Upper Ocean Currents (PROTEUS) moorings with downward-looking ADCPs mounted on the buoy's bridle and several mechanical current meters attached to the mooring line. All other ADCPs were upward-looking subsurface-moored ADCPs. Figure 3 shows the zonal ADCP currents along the equator, and Fig. 4a shows the meridional ADCP currents at the central $0^{\circ}, 156^{\circ} \mathrm{E}$ site. The ADCPs measured currents with at least hourly temporal resolution and $8-10-\mathrm{m}$ vertical resolution. The depths of the top and bottom bins (Table 1) depend upon the geometry of the ADCP placement, but typically were $14-30 \mathrm{~m}$ and 230-280 $\mathrm{m}$, respectively. ADCPs assume that the sound reflectors are small particles and phytoplankton moving passively with the currents. Fish swarming near the surface buoys are actively swimming reflectors and thus can bias downward-looking ADCP data. However, analysis of the ADCP echo intensities and comparisons with the mechanical current meters indicate that fish biases were minimal at COARE sites (Plimpton et al. 1997).

For the purposes of our analyses, currents were extrapolated to the surface by assuming constant flow above the top measurement level. To fill gaps in the zonal current data at the central site $\left(0^{\circ}, 156^{\circ} \mathrm{E}\right)$, current data from the four nearby sites $\left(0^{\circ}, 154^{\circ} \mathrm{E} ; 0^{\circ}, 157.5^{\circ} \mathrm{E}\right.$; $\left.0.75^{\circ} \mathrm{N}, 156^{\circ} \mathrm{E} ; 0.75^{\circ} \mathrm{S}, 156^{\circ} \mathrm{E}\right)$ were used to generate a frequency-dependent transfer function. The filled data are valid for timescales greater than approximately 5 days and thus the filled data were smoothed with a 5-day triangular filter (3-day cutoff, 7-day half amplitude) and subsampled once per day.

One objective of the ADCP array was the computation of vertical velocity based on estimations of the horizontal divergence at the central $0^{\circ}, 156^{\circ} \mathrm{E}$ site $(\mathrm{Hel}-$ ber and Weisberg 1998). From conservation of mass, a horizontal divergence implies vertical velocity convergence. Thus vertical velocity (Fig. 4b) can be computed by vertically integrating the horizontal divergence estimate and assuming the boundary condition of no vertical flow at the surface (e.g., Wyrtki 1981; Halpern and Freitag 1987; Weingartner and Weisberg 1991; Helber and Weisberg 1998; Weisberg and Qiao 1999). Note that during the second year (February 1993 through March 1994), zonal divergence was estimated with a side finite difference $\left(0^{\circ}, 157.5^{\circ} \mathrm{E}\right.$ minus $\left.0^{\circ}, 156^{\circ} \mathrm{E}\right)$. All other zonal 

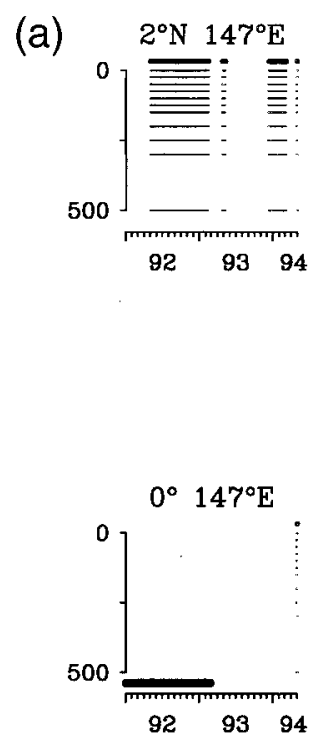

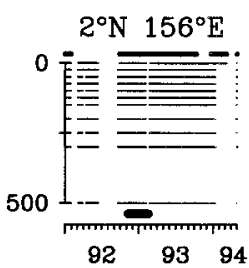

$0.75^{\circ} \mathrm{N} 156^{\circ} \mathrm{E}$
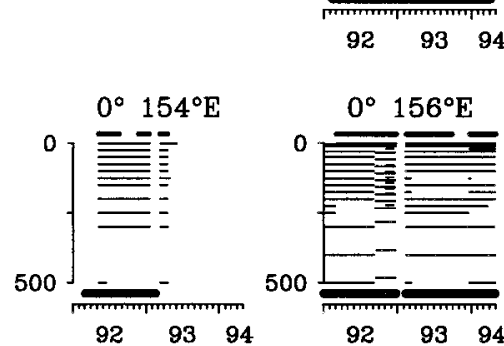
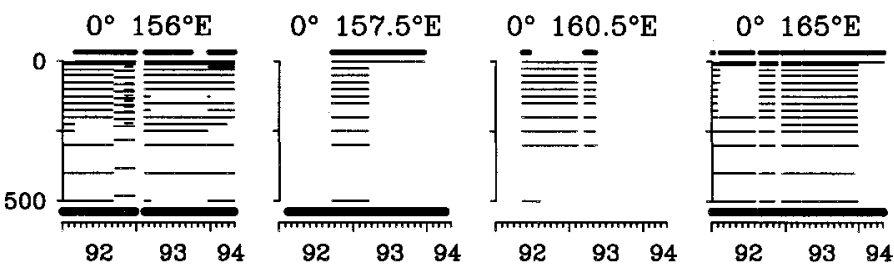

$0.75^{\circ} \mathrm{S} 156^{\circ} \mathrm{E}$
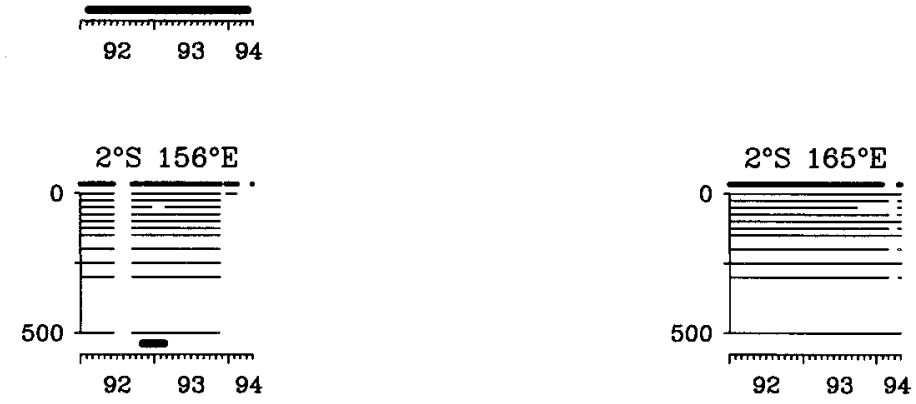

ADCP Current (b)

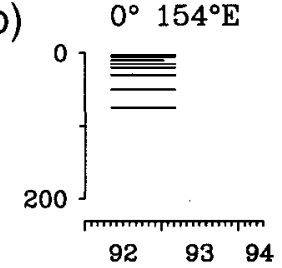

$0^{\circ} 156^{\circ} \mathrm{E}$

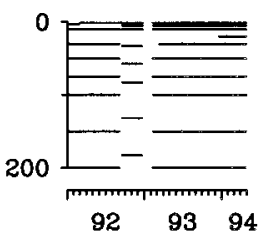

$0^{\circ} 160.5^{\circ} \mathrm{E}$

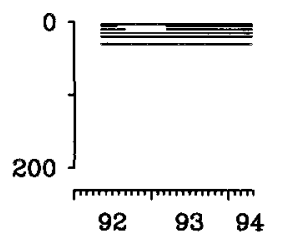

$0^{\circ} 165^{\circ} \mathrm{E}$

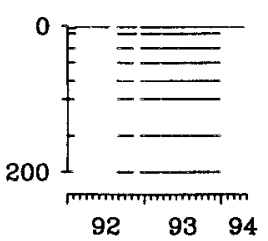

\section{SEACAT Temperature and Salinity}

FIG. 2. (a) Data availability of EMA wind, subsurface temperature, and ADCP currents. The standard TAO depths for subsurface temperature in this region are $1 \mathrm{~m}, 25 \mathrm{~m}, 50 \mathrm{~m}, 75 \mathrm{~m}, 100 \mathrm{~m}, 125 \mathrm{~m}, 150 \mathrm{~m}, 200 \mathrm{~m}, 250 \mathrm{~m}, 300 \mathrm{~m}$, and $500 \mathrm{~m}$. Some moorings had enhanced vertical resolution for temperature beyond these standard depths. (b) Data availability of EMA SEACAT temperature and salinity along equator.

and meridional divergence estimates used central finite differences.

\section{b. Winds}

Each TAO buoy had as standard instrumentation an RM Young wind sensor and vane mounted atop the buoy tower at $4 \mathrm{~m}$ above the ocean surface (Fig. 1). Wind speed and direction were sampled at $2 \mathrm{~Hz}$ and vector averaged over six minutes once per hour. As in Cronin and McPhaden (1997), wind stress was computed using hourly surface meteorological data at $0^{\circ}, 156^{\circ} \mathrm{E}$ (wind speed and direction at $4 \mathrm{~m}$, air temperature and relative humidity at $3 \mathrm{~m}$, shortwave radiation when available, 
TABLE 1. ADCP placement. Upward and downward looking ADCPs are specified as u and d in column 3. Subsurface moored upwardlooking ADCPs were anchored typically 5-km from the corresponding surface mooring site. 153.6-kHz ADCPs measure horizontal currents in 8-10-m bins. The center depth of the top and bottom bins are listed in columns 4 and 5. Institutions listed in column 6 were responsible for collecting and processing the ADCP data. The upward-looking ADCP at $0^{\circ}, 156^{\circ} \mathrm{E}$ was loaned to PMEL by USF.

\begin{tabular}{|c|c|c|c|c|c|}
\hline Site & Date & Orient & Top bin $(\mathrm{m})$ & Bottom bin (m) & Institution \\
\hline $0^{\circ}, 147^{\circ} \mathrm{E}$ & 1 Jan $92-23$ Feb 93 & $\mathrm{u}$ & 50 & 230 & Tokai U. \\
\hline $0^{\circ}, 154^{\circ} \mathrm{E}$ & 1 Mar $92-16$ Dec 93 & $\mathrm{u}$ & 20 & 240 & Tokai U. \\
\hline $0^{\circ}, 156^{\circ} \mathrm{E}$ & 29 Aug $91-8$ Mar 93 & $\mathrm{~d}$ & 14 & $230-255$ & PMEL \\
\hline $0^{\circ}, 156^{\circ} \mathrm{E}$ & 12 Mar 93-27 Apr 94 & $\mathrm{u}$ & 20 & 260 & PMEL \\
\hline $0^{\circ}, 157.5^{\circ} \mathrm{E}$ & $12 \mathrm{Feb} 92-31$ Mar 94 & $\mathrm{u}$ & 30 & 280 & USF \\
\hline $0^{\circ}, 165^{\circ} \mathrm{E}$ & 8 Aug $91-16$ Apr 94 & $\mathrm{~d}$ & 14 & $220-240$ & PMEL \\
\hline $0.75^{\circ} \mathrm{N}, 156^{\circ} \mathrm{E}$ & 12 Feb 92-3 Apr 94 & $\mathrm{u}$ & 30 & 280 & USF \\
\hline $0.75^{\circ} \mathrm{S}, 156^{\circ} \mathrm{E}$ & 12 Feb $92-2$ Apr 94 & $\mathrm{u}$ & 30 & 280 & USF \\
\hline
\end{tabular}

and SST at $1 \mathrm{~m}$ ) and the COARE v2.5b bulk flux algorithm (Fairall et al. 1996a,b). The algorithm follows the standard Monin-Obukhov similarity approach for near-surface meteorological measurements, but includes models for the ocean's cool skin and diurnal warm layer to estimate the skin temperature from measurements of the bulk SST at 1-m depth. The 5-day triangular filtered wind stress time series at $0^{\circ}, 156^{\circ} \mathrm{E}$ is shown in Fig. 5.

\section{c. Subsurface temperature, salinity, and dynamic height}

Dynamic height depends upon a vertical integral of temperature and salinity above some reference level. As shown in Fig. 2a, TAO moorings had daily averaged temperature data at depths ranging from $1 \mathrm{~m}$ to $500 \mathrm{~m}$. As shown in Fig. 2b, enhancements included Seabird SEACAT temperature and conductivity sensors (from which salinity is computed) down to $200 \mathrm{~m}$ at $0^{\circ}, 156^{\circ} \mathrm{E}$ and $0^{\circ}, 165^{\circ} \mathrm{E}$ and down to only $70 \mathrm{~m}$ at $0^{\circ}, 154^{\circ} \mathrm{E}$ and $30 \mathrm{~m}$ at $0^{\circ}, 160.5^{\circ} \mathrm{E}$ (Cronin and McPhaden 1998; Freitag et al. 1999). To extrapolate the salinity profiles to the temperature measurement levels, a slowly varying, spatially dependent temperature-salinity $(T-S)$ curve was computed by blending CTD and buoy temperature and salinity measurement pairs using an optimal interpolation scheme described in the appendix. Quality control and postprocessing of SEACAT data are described by Cronin and McPhaden (1998) and Freitag et al. (1999).

These daily averaged temperature and salinity data were then used to compute dynamic height relative to $500 \mathrm{db}$. At some sites the bottom thermistor(s) failed and the deepest thermistor was at $250 \mathrm{~m}$ or $300 \mathrm{~m}$ (Fig. 2 ). For these periods, the 500-db referenced dynamic height was computed based on a regression analysis, for example, $300 \mathrm{db}$ versus $500 \mathrm{db}$ referenced dynamic heights. The regressed dynamic heights typically had a root-mean-square error of roughly 0.6 dynamic centimeters at the surface.

In order to investigate the variability in the pressure gradient due to salinity, dynamic height was also computed using only temperature data [a climatological $T-S$ curve (Levitus and Boyer 1994; Levitus et al. 1994) was used to estimate salinity from temperature]. The differences between the dynamic height estimates are due to variations in the $T-S$ curve and can be interpreted as the dynamic height due to anomalous variability in salinity. At $0^{\circ}, 156^{\circ} \mathrm{E}$ the mean, rms, maximum, and minimum differences between the surface dynamic heights computed with and without observed salinity were 5, 6,10 , and -2 dyn $\mathrm{cm}$, respectively. These differences are considerable in relation to the 6 dyn $\mathrm{cm}$ standard deviation of the surface dynamic height at $0^{\circ}, 156^{\circ} \mathrm{E}$. However, since changes in the $T-S$ curve are often coherent over several degrees of longitude, salinity variations typically have a less dramatic effect on the zonal pressure gradient. The effects of salinity variations on pressure gradients and the momentum balance are analyzed further in section 3 .

\section{Methodology}

In contrast to the SEC and EUC current structure found in the central equatorial Pacific, the western equatorial Pacific zonal currents show complex and variable vertical structures (Fig. 3) with current reversals both in depth and time. The depths of current reversals (i.e., zero current) roughly correspond to the depths of the $28^{\circ} \mathrm{C}$ and $20^{\circ} \mathrm{C}$ isotherms. Note that the $28^{\circ} \mathrm{C}$ isotherm is near the top of the thermocline and the location at which it outcrops defines the boundary of the western equatorial Pacific "warm pool." Likewise, the $20^{\circ} \mathrm{C}$ isotherm is near the middle of the thermocline and its variability is often used as a proxy for thermocline depth variability (e.g., Rebert et al. 1985; Kessler et al. 1995). Thus we define three layers: a "surface layer" above the top of the thermocline from the surface to the depth of the $28^{\circ} \mathrm{C}$ isotherm (or $25 \mathrm{~m}$, whichever is deeper), an "intermediate layer" in the upper thermocline between the base of the surface layer and the $20^{\circ} \mathrm{C}$ isotherm, and an "Equatorial Undercurrent layer" between the $20^{\circ} \mathrm{C}$ isotherm and the bottom ADCP bin $(240 \mathrm{~m})$. Because of the large variability within the surface layer, the record-length mean currents were near zero above $100 \mathrm{~m}$ (Fig. 3). In contrast, within the EUC layer, the currents were always eastward.

In order to understand the dynamics that give rise to 


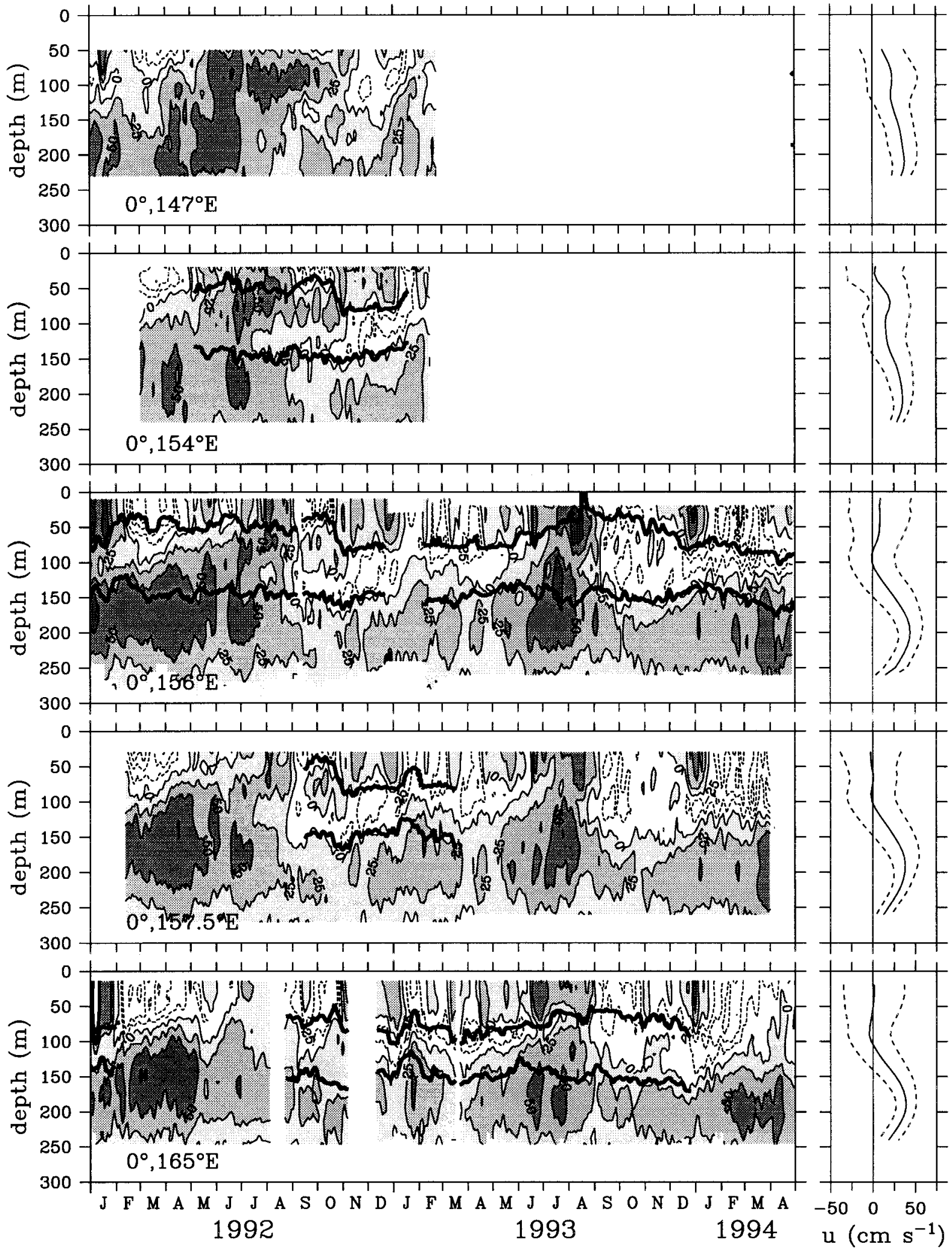

FIg. 3. Five-day triangular filtered zonal currents along the equator at $147^{\circ} \mathrm{E}, 154^{\circ} \mathrm{E}, 156^{\circ} \mathrm{E}, 157.5^{\circ} \mathrm{E}$, and $165^{\circ} \mathrm{E}$. The contour interval (CI) is $25 \mathrm{~cm} \mathrm{~s}^{-1}$. Eastward flow is shaded. The upper and lower thick lines are, respectively, $28^{\circ} \mathrm{C}$ and $20^{\circ} \mathrm{C}$ isotherms as measured by the corresponding TAO mooring. Right panels show the mean zonal currents and standard deviation envelope for each site along the equator. 

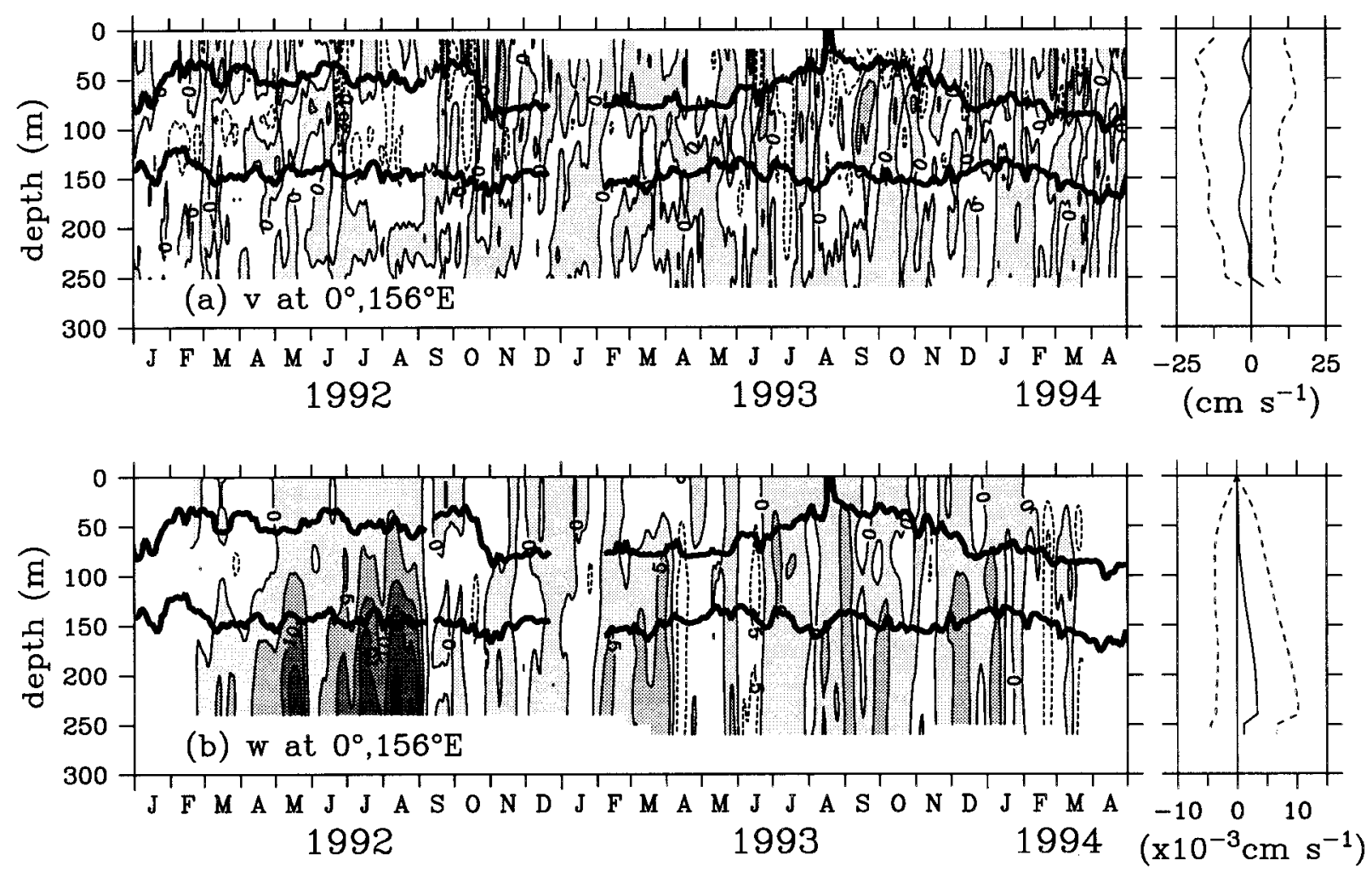

FIG. 4. (a) Five-day filtered meridional velocity as measured by the $0^{\circ}, 156^{\circ} \mathrm{E}$ ADCP; $\mathrm{CI}$ is $25 \mathrm{~cm} \mathrm{~s}^{-1}$. Northward flow is shaded. Right panel shows the mean and standard deviation envelope of the 5-day filtered meridional flow. (b) Fifteen-day triangular filtered vertical velocity at $0^{\circ}, 156^{\circ} \mathrm{E}$ as computed from mass budget in units $10^{-3} \mathrm{~cm} \mathrm{~s}^{-1}$. The CI is $5 \times 10^{-3} \mathrm{~cm} \mathrm{~s}^{-1}$. Upwelling is shaded. Right panel shows the mean and the standard deviation envelope of the 5-day-filtered vertical velocity. The upper and lower thick lines in the left panels are, respectively, the $28^{\circ} \mathrm{C}$ and $20^{\circ} \mathrm{C}$ isotherms at $0^{\circ}, 156^{\circ} \mathrm{E}$.

these layered jet structures, the zonal momentum balance is evaluated at the $0^{\circ}, 156^{\circ} \mathrm{E}$ central site both as a function of depth and within the three different layers. Forcing whose sign and magnitude change in successively deeper layers can cause complex vertical structures with accelerations in opposing directions, giving rise to reversing jets.

The zonal momentum balance can be written as

$$
u_{t}-\beta y v=-\frac{1}{\rho} P_{x}-u u_{x}-v u_{y}-w u_{z}+\frac{1}{\rho} \tau_{z},
$$

where subscripts $t, x, y$, and $z$ indicate temporal, zonal, meridional, and vertical derivatives; $(u, v, w)$ are, respectively, the zonal, meridional, and vertical flow; $\beta$ is the meridional gradient in the planetary vorticity; $y$ is the meridional displacement from the equator, which is zero for our analysis of equatorial momentum balance; $P_{x}$ is the zonal pressure gradient; $\rho$ is the ocean density; and $\tau$ is the zonal stress. To derive the layer-averaged zonal momentum balance, the depth-dependent balance (1) is vertically averaged from the top of the layer to the bottom of the layer. Doing this, the layer-averaged zonal momentum balance can be written as

$$
\begin{aligned}
\left\langle u_{t}\right\rangle_{i}-\beta y\langle v\rangle_{i}= & -\left\langle\frac{1}{\rho} P_{x}\right\rangle_{i}-\left\langle u u_{x}\right\rangle_{i}-\left\langle v u_{y}\right\rangle_{i} \\
& -\left\langle w u_{z}\right\rangle_{i}+\frac{\tau_{i-1}-\tau_{i}}{\rho\left(h_{i}-h_{i-1}\right)},
\end{aligned}
$$

where $\langle()\rangle_{i}$ is the layer $i$ vertical average defined by the layer depths $z=-h_{i-1}$ and $z=-h_{i}$ :

$$
\langle()\rangle_{i}=\frac{1}{h_{i}-h_{i-1}} \int_{-h_{i}}^{-h_{i-1}}(\mathrm{)}) d z
$$

$\tau_{i}$ is the zonal stress at $z=-h_{i}$, and $\tau_{0}$ is the zonal wind stress at the ocean surface. In both the depthdependent (1) and layer-averaged (2) zonal momentum balance, the first term on the lhs is the local acceleration (also referred to as the tendency rate), the second term is zero on the equator, the first term on the rhs is the zonal pressure gradient force, the second, third, and fourth terms are the nonlinear advection terms, and the final term on the rhs is the vertical divergence of the turbulent stress (the horizontal stress divergence is assumed to be negligible). The layers $h_{i}$ are arbitrary; however, as discussed above, we define $h_{1}$ as the $28^{\circ} \mathrm{C}$ isotherm depth (or $25 \mathrm{~m}$, whichever is deeper), $h_{2}$ as 

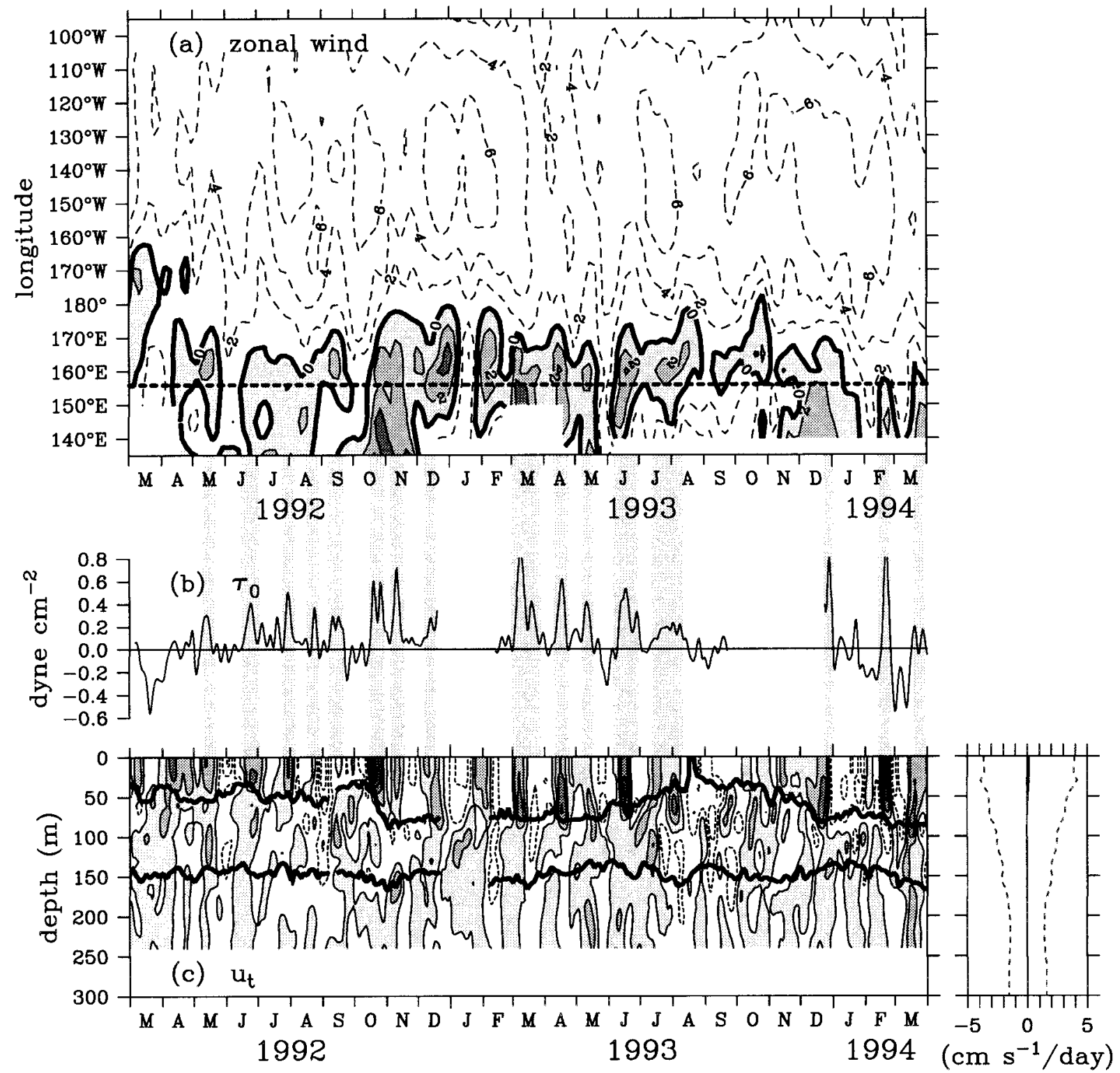

FIG. 5. (a) Time-longitude plot of the 5-day gridded zonal winds along the equator as measured by the TAO array: CI is $2 \mathrm{~m} \mathrm{~s}^{-1}$; positive values are shaded. (b) Five-day filtered zonal wind stress at $0^{\circ}, 156^{\circ} \mathrm{E}$. Large positive (westerly) wind stress events are striped gray. (c) Fifteen-day filtered local zonal acceleration at $0^{\circ}, 156^{\circ} \mathrm{E}$ : CI is $2 \mathrm{~cm} \mathrm{~s}^{-1} /$ day; eastward accelerations are shaded. Right panel shows the record length mean and standard deviation envelope of the local acceleration.

the $20^{\circ} \mathrm{C}$ isotherm depth, $h_{3}$ as $240 \mathrm{~m}$ (near the bottom ADCP bin depth), and $h_{0}$ as the air-sea interface $(0 \mathrm{~m})$.

The pressure gradient force at $0^{\circ}, 156^{\circ} \mathrm{E}$ shown in Fig. 6a was estimated using the zonal gradient of the 5-day triangular filtered 500-db referenced dynamic height. Although deep flow is not completely motionless (e.g., Firing et al. 1998), the pressure gradient at 500 $\mathrm{m}$ is expected to be relatively small near the equator. The zonal gradient of the dynamic height was computed as a "centered" difference between $0^{\circ}, 160.5^{\circ} \mathrm{E}$ and $0^{\circ}$, $154^{\circ} \mathrm{E}$ for the periods 10 May $1992-20$ January 1993 and 13 March-18 April 1993, as the "narrow side difference" between $0^{\circ}, 160.5^{\circ} \mathrm{E}$ and $0^{\circ}, 156^{\circ} \mathrm{E}$ for the 14 day period from 19 April through 2 May 1993, and as a "wide side difference" between $0^{\circ}, 165^{\circ} \mathrm{E}$ and $0^{\circ}$, $156^{\circ} \mathrm{E}$ for all other periods. The pressure gradient estimated with a wide side difference has less high-frequency, localized variability. Consequently, the wind burst pressure gradient response is best analyzed during the well-resolved period between May 1992 and April 1993.

To address the dynamical influence of salinity vari- 

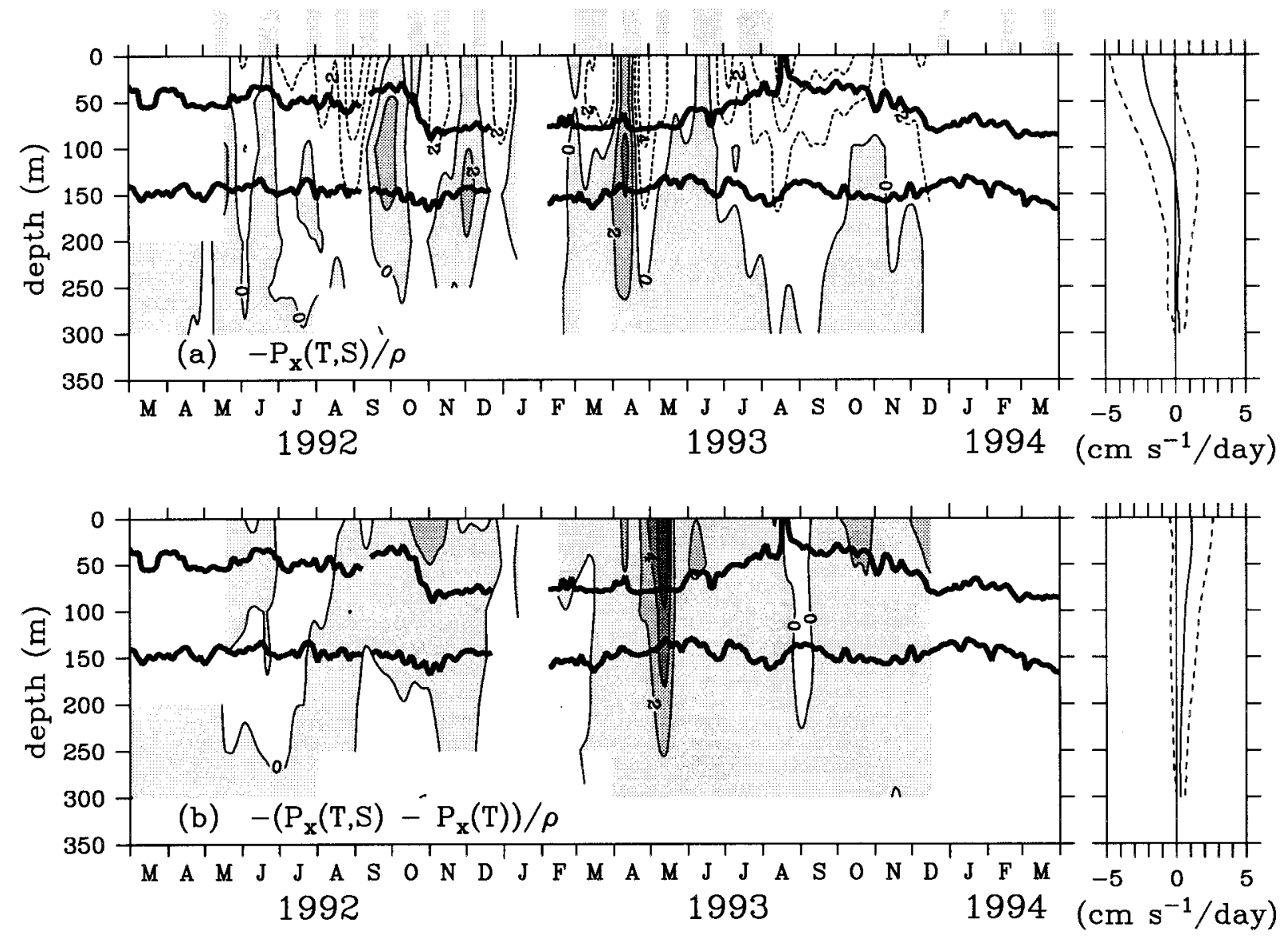

FIG. 6. (a) Fifteen-day triangular filtered zonal force due to the zonal gradient in dynamic height relative to $500 \mathrm{db}$ computed using observed temperature and salinity data. Westerly wind stress events are striped gray as in Fig. 5.(b) The difference between the zonal pressure gradient force computed using temperature and salinity, and computed with temperature only. In both, the CI is $2 \mathrm{~cm} \mathrm{~s}^{-1}$ per day and eastward forcing is shaded. The upper and lower thick lines in the left panels are, respectively, the $28^{\circ} \mathrm{C}$ and $20^{\circ} \mathrm{C}$ isotherms at $0^{\circ}, 156^{\circ} \mathrm{E}$. Right panels show the mean profile of the time series and its standard deviation envelope.

ability, the pressure gradient force was also computed using only temperature data (salinity was computed from temperature using the Levitus climatological $T-S$ curves). The difference between the pressure gradient force computed with observed temperature and salinity and the pressure gradient computed using temperature only is shown in Fig. $6 \mathrm{~b}$ and can be interpreted as the pressure gradient force due to anomalous salinity variability. At the surface, the mean, rms, maximum, and minimum differences are respectively $0.8,1.7,10.5$, and $-1.7 \mathrm{~cm} \mathrm{~s}^{-1} /$ day, which should be compared to the mean, rms, and maximum and minimum of the surface pressure gradient force (respectively, -2.6, 3.5, 4.0, and $-9.9 \mathrm{~cm} \mathrm{~s}^{-1} /$ day). Note that a 3 dyn $\mathrm{cm}$ change over 9 degrees of longitude corresponds to a $2.6 \mathrm{~cm} \mathrm{~s}^{-1} /$ day acceleration.

As shown in Fig. 6b, the largest differences in the pressure gradient force estimates tend to occur at the surface, presumably due to the passage of salinity fronts (e.g., October 1992, April-May 1993, and October
1993) (Cronin and McPhaden 1998). However, variability in the salinity maximum between depth 100 and $200 \mathrm{~m}$ had a relatively larger effect on the weaker subsurface pressure gradient and local tendency rate. In particular, during the boreal spring and fall of 1993, when the pressure gradient was computed using a wide side difference (between $0^{\circ}, 165^{\circ} \mathrm{E}$ and $0^{\circ}, 156^{\circ} \mathrm{E}$ ), salinity variability often controlled the sign of the pressure gradient in the EUC layer. Finally, we note that in the layer balance, the cross correlations with local tendency rate were substantially lower when the pressure gradient force was computed using temperature only $(0.19,0.23$, and 0.11 for the surface, intermediate, and EUC layers, respectively, as compared to $0.35,0.37$, and 0.23 ).

The local tendency rate (Fig. 5c) and advection terms (Fig. 7) were computed using 5-day filtered daily ( $u, v$, $w)$ velocity data. In particular, the local tendency rate was estimated as a 3-day centered finite difference of zonal velocity at $0^{\circ}, 156^{\circ} \mathrm{E}$. Zonal advection was computed using a centered finite difference of the zonal 



FIG. 7. (a) Zonal, (b) meridional, and (c) vertical advection, and (d) the net 3D advection of zonal flow. The upper and lower thick lines are, respectively, the $28^{\circ} \mathrm{C}$ and $20^{\circ} \mathrm{C}$ isotherms: $\mathrm{CI}$ is $2 \mathrm{~cm} \mathrm{~s}^{-1}$ /day; positive advections (inducing eastward accelerations) are shaded. Westerly wind stress events are striped gray as in Fig. 5. Mean and standard deviation envelopes of the time series are shown in the panels on the right.

velocity $\left(0^{\circ}, 157.5^{\circ} \mathrm{E}\right.$ minus $\left.0^{\circ}, 154^{\circ} \mathrm{E}\right)$ from March 1992 through February 1993 and a side finite difference $\left(0^{\circ}\right.$, $157.5^{\circ} \mathrm{E}$ minus $\left.0^{\circ}, 156^{\circ} \mathrm{E}\right)$ from February 1993 through March 1994. Meridional advection was computed using an upstream finite difference throughout the entire record, and vertical advection was computed using a centered finite difference over the 10-m ADCP bin size.

For the sake of consistency between the layered and 

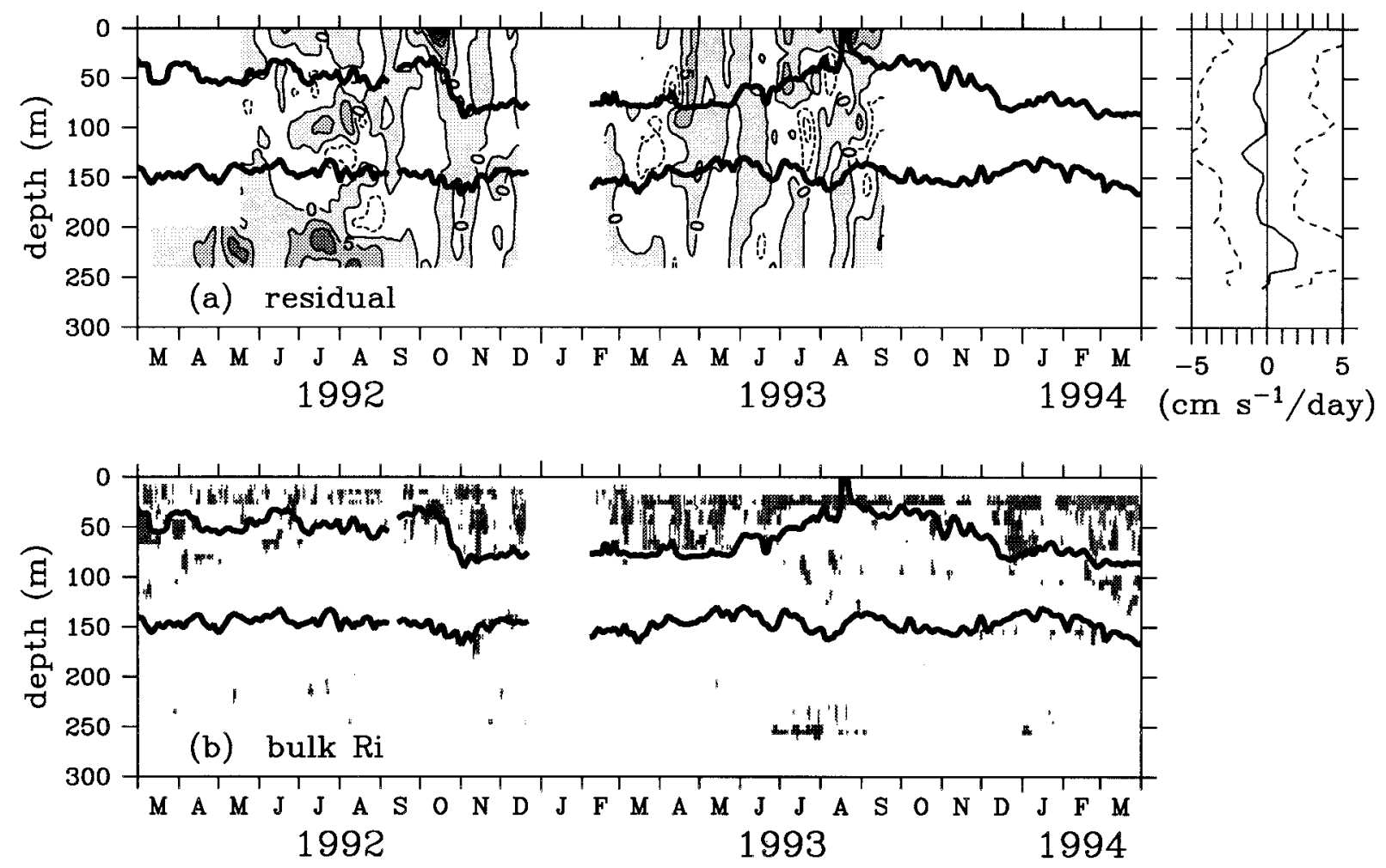

FIG. 8. (a) Residual profile time series: $\mathrm{CI}$ is $5 \mathrm{~cm} \mathrm{~s}^{-1} /$ day; eastward forcing is shaded. The mean profile and standard deviation envelope are shown in the right panel. (b) Bulk Richardson number values less than 1 . The upper and lower thick lines are, respectively, the $28^{\circ} \mathrm{C}$ and $20^{\circ} \mathrm{C}$ isotherms.

depth-dependent analyses, we decompose the zonal stress $\tau$ into a portion $\tau_{b}$ that represents the projection of the wind stress onto the surface layer, and a deviation $\tau^{\prime}$ from this wind stress projection:

$$
\tau_{b}=\tau_{0}\left(\frac{z+h_{1}}{h_{1}}\right) H\left(z+h_{1}\right) \quad \tau^{\prime}=\tau-\tau_{b},
$$

where $H\left(z+h_{1}\right)$ is the Heaviside operator equal to 1 and 0 , respectively, above and below $z=-h_{1}$. Thus, $\tau_{b}$ is equal to the wind stress $\tau_{0}$ at the surface and zero at and below the base of the surface layer, and the vertical divergence of $\tau_{b}$ in (1) is equivalent to the wind forcing term in the layer balance (2): $\tau_{b z} / \rho=\tau_{0} / \rho h_{1}$. This wind stress body force was estimated using hourly wind stress and surface-layer depth time series at $0^{\circ}$, $156^{\circ} \mathrm{E}$ and was subsequently filtered with a 5-day triangular filter and subsampled to once per day.

In general, most terms could be estimated at the $0^{\circ}$, $156^{\circ} \mathrm{E}$ central site. The term $\tau_{z}^{\prime} / \rho$ was estimated as a residual of the zonal momentum balance for periods in which all other terms could be evaluated. The residual, however, also contains the accumulation of sampling and measurement errors and therefore caution is warranted when interpreting it in terms of physics. The depth-dependent residual is shown in Fig. 8 and will be discussed in section $4 \mathrm{~d}$.
For presentation purposes, the depth-dependent tendency rate (Fig. 5c), zonal pressure gradient force (Fig. 6), nonlinear terms (Fig. 7), and residual (Fig. 8) were filtered with a 15-day triangular filter (8-day cutoff, 18day half amplitude). However, in order to analyze processes occurring on wind burst timescales, the layer balance terms shown in Figs. 9-11 were filtered with a 5-day triangular filter. Likewise, all means and standard deviations (Table 2, Figs. 5-8), and cross correlations (Table 3, Figs. 12, 13) were computed using the 5-day triangular filtered time series.

\section{Results}

Over the record length, the mean tendency rate is near zero both at the surface and at depth (Fig. 5c, Table 2). However, instantaneously, the flow was far from steady, particularly at the surface. Surface currents were strong and variable with frequent changes in direction (Fig. 3), and correspondingly, surface current accelerations were large and variable, with frequent changes in direction (Fig. 5c). Much of this variability can be attributed to direct wind forcing. In contrast to the steady trades found in the central equatorial Pacific, the western equatorial Pacific was characterized by weak trades punctuated by westerly wind 

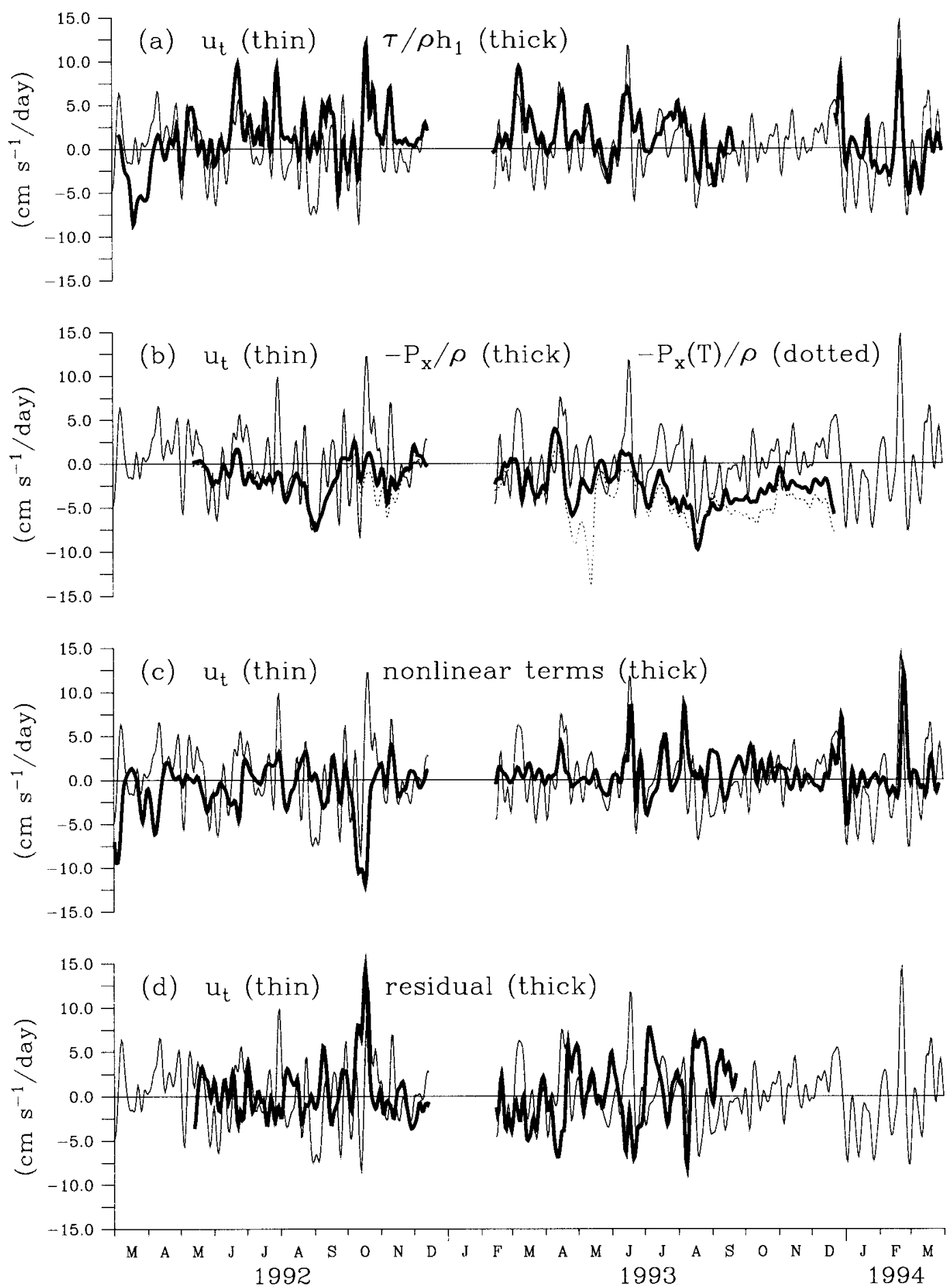

FIG. 9. Surface-layer zonal momentum balance in units centimeters per second per day. The surface-layer tendency rate is repeated as a thin line in each panel, with the following terms shown as a thick line: (a) surface wind forcing; (b) pressure gradient force (the pressure gradient force computed using temperature only is shown as a dotted line); (c) the net zonal, meridional, and vertical advection; and (d) the residual of the surface-layer balance. The surface layer is defined as the layer between the surface interface $(z=0)$ and the depth of the $28^{\circ} \mathrm{C}$ isotherm (or $25 \mathrm{~m}$, whichever is deeper). All terms are filtered with a 5-day triangular filter. 

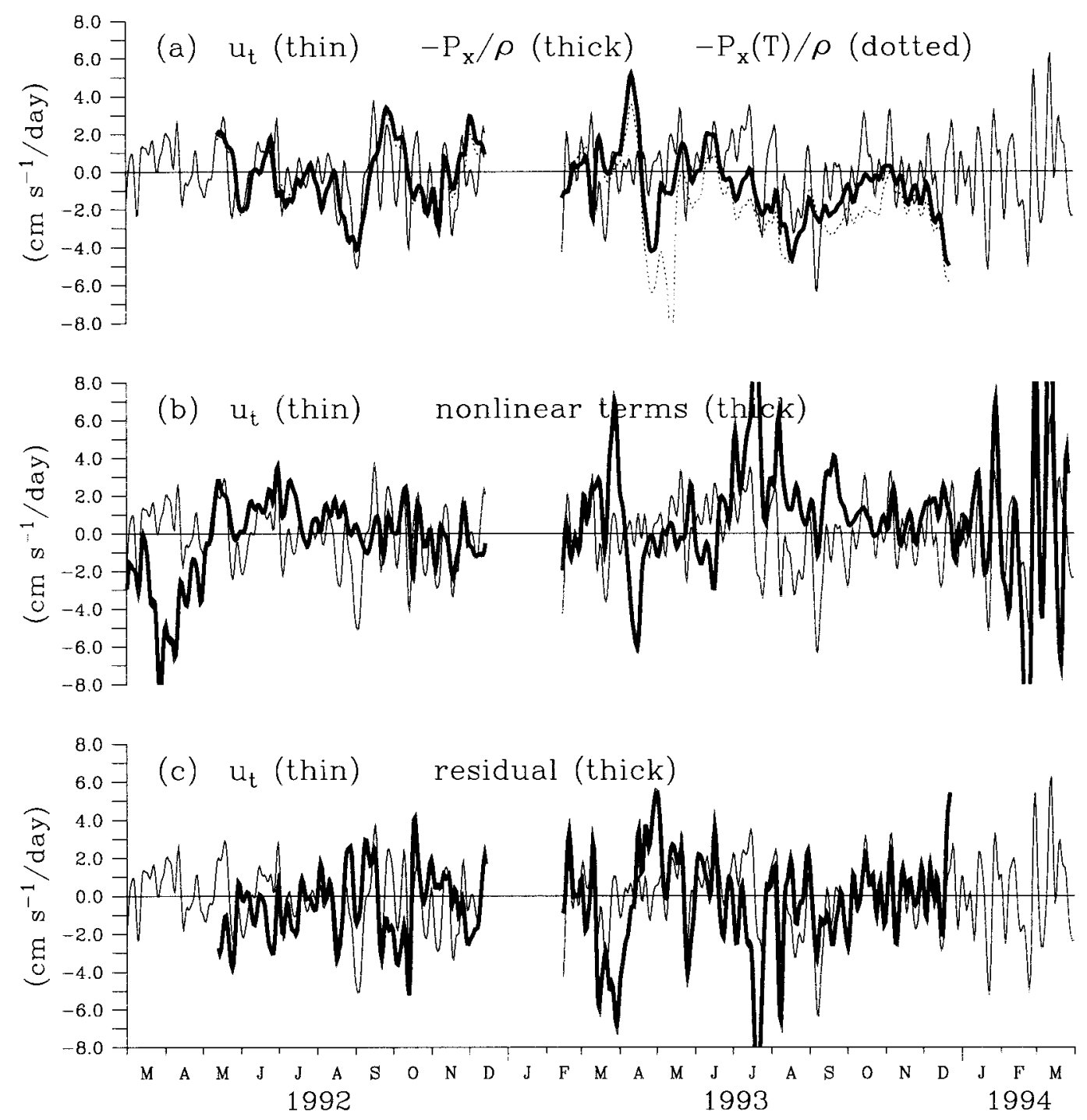

FIG. 10. Intermediate-layer zonal momentum balance in units centimeters per second per day. The intermediatelayer tendency rate is repeated as a thin line in each panel, with the following terms shown as a thick line: (a) pressure gradient force (the pressure gradient force computed using temperature only is shown as a dotted line); (b) the net zonal, meridional, and vertical advection; and (c) the residual of the intermediate-layer balance. The intermediate layer is defined as the layer below $25 \mathrm{~m}$ between the $28^{\circ} \mathrm{C}$ and $20^{\circ} \mathrm{C}$ isotherm surfaces. All terms are filtered with a 5-day triangular filter.

bursts (Fig. 5a). At $0^{\circ}, 156^{\circ} \mathrm{E}$ the record-length mean zonal wind stress was eastward $\left(0.08 \mathrm{dyn}^{-2}\right)$, and a factor of 3 smaller than the standard deviation of the 5-day filtered zonal wind stress $\left(0.25 \mathrm{dyn}^{-2}\right)$. Consequently, local wind forcing at $0^{\circ}, 156^{\circ} \mathrm{E}$ had relatively frequent changes in direction (Fig. 5b). As shown in Fig. 12 and Tables 2 and 3, this local wind forcing was both highly correlated with and of similar magnitude to the local tendency rate. In fact, of all the terms in the zonal momentum balance, the surfacelayer tendency rate was most highly correlated (0.59) with the local wind stress forcing. As a result, surface current anomalies tended to form in the direction of the wind stress approximately 3 days after the peak wind stress (Fig. 13). Approximately 14 days after the peak wind stress, however, subsurface zonal current anomalies tended to form in a direction opposing the local zonal wind stress. As we will show, these subsurface current anomalies were due in part to the effects of wind forcing on the zonal pressure gradient.

In general, all terms in the momentum balance had large variability and were significantly correlated with the local tendency rate (Fig. 12, Table 3). In particular, the pressure gradient force appears to be important in all three layers, the residual had high correlations with the local tendency rate in the intermediate layer, and nonlinear terms were large and appear to gain importance with depth. We discuss each term in detail below. 

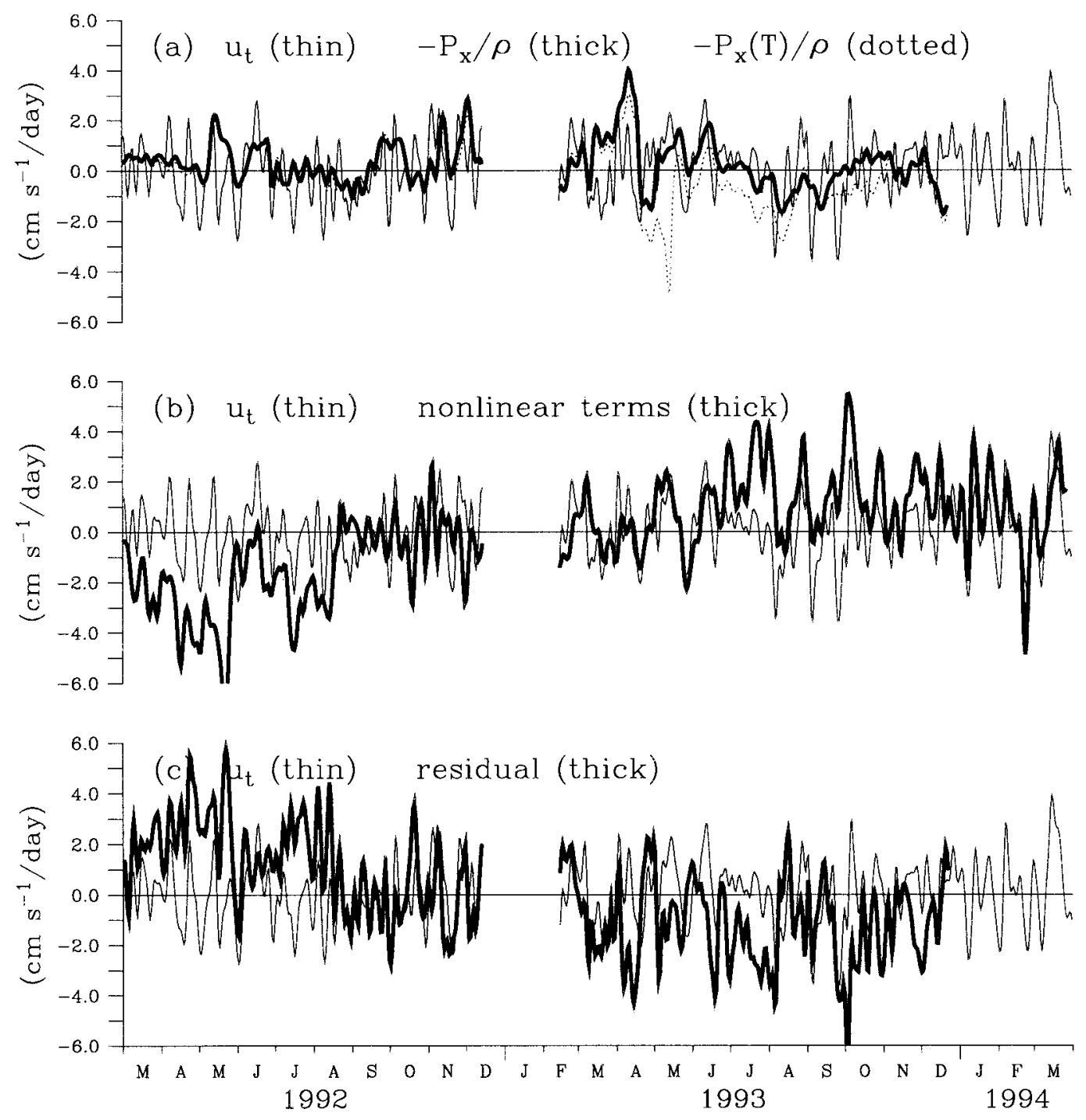

FIG. 11. Same as Fig. 10 but for the EUC layer. The EUC layer is defined as the layer between $20^{\circ} \mathrm{C}$ and $240 \mathrm{~m}$.

TABLE 2. Means, $90 \%$ uncertainty of the means, and standard deviations of 5-day-filtered $0^{\circ}, 156^{\circ} \mathrm{E}$ layer-averaged momentum balance. The units of all terms are centimeters per second per day. Values in parentheses indicate mean estimates that are insignificant at the $90 \%$ confidence level. The surface layer is defined as the layer between the surface interface $(z=0)$ and the depth of the $28^{\circ} \mathrm{C}$ isotherm (or 25 $\mathrm{m}$, whichever is deeper). The intermediate layer is the layer below $25 \mathrm{~m}$ between the $28^{\circ} \mathrm{C}$ and the $20^{\circ} \mathrm{C}$ isotherms, and the Equatorial Undercurrent (EUC) layer is the layer between the $20^{\circ} \mathrm{C}$ isotherm and $240 \mathrm{~m}$.

\begin{tabular}{|c|c|c|c|c|c|c|}
\hline & \multicolumn{2}{|c|}{ Surface layer } & \multicolumn{2}{|c|}{ Intermediate layer } & \multicolumn{2}{|c|}{ EUC layer } \\
\hline & Mean & Std dev & Mean & Std dev & Mean & Std dev \\
\hline$u_{t}$ & $(0.19 \pm 0.42)$ & 3.47 & $(-0.07 \pm 0.27)$ & 1.76 & $(0.01 \pm 0.16)$ & 1.27 \\
\hline$\tau_{0} /\left(\rho h_{1}\right)$ & $1.05 \pm 0.66$ & 3.09 & N/A & N/A & N/A & N/A \\
\hline$-P_{x} / \rho$ & $-2.23 \pm 0.77$ & 2.26 & $-0.57 \pm 0.45$ & 1.76 & $(0.26 \pm 0.28)$ & 0.93 \\
\hline$-u u_{x}$ & $(-0.23 \pm 0.31)$ & 1.84 & $(0.37 \pm 0.53)$ & 1.47 & $0.36 \pm 0.35$ & 1.05 \\
\hline$-v u_{y}$ & $0.13 \pm 0.13$ & 1.03 & $(-0.12 \pm 0.13)$ & 0.91 & $(-0.01 \pm 0.07)$ & 0.53 \\
\hline$-w u_{z}$ & $0.13 \pm 0.13$ & 1.07 & $(0.10 \pm 0.29)$ & 2.36 & $-0.45 \pm 0.36$ & 1.35 \\
\hline$-\mathbf{U} \cdot \nabla u$ & $(0.02 \pm 0.33)$ & 2.67 & $(0.35 \pm 0.71)$ & 2.94 & $(-0.10 \pm 0.50)$ & 2.07 \\
\hline Residual & $(0.33 \pm 0.78)$ & 3.30 & $-0.45 \pm 0.28$ & 2.29 & $(-0.04 \pm 0.50)$ & 2.10 \\
\hline
\end{tabular}


TABLE 3. Cross-correlations between the 5-day filtered layer-averaged local tendency rate and forcing terms. Uncertainties represent the correlation for the null hypothesis at the $90 \%$ confidence level. Values in parentheses indicate cross-correlations that are insignificant at the $90 \%$ confidence level.

\begin{tabular}{lccc}
\hline \hline$R_{x y}$ with $u_{t}$ & Surface layer & Intermediate layer & EUC layer \\
\hline$\tau_{0} /\left(\rho h_{1}\right)$ & $0.59 \pm 0.14$ & N/A & N/A \\
$-P_{x} / \rho$ & $0.35 \pm 0.15$ & $0.37 \pm 0.15$ & $0.23 \pm 0.13$ \\
$-u u_{x}$ & $(0.03 \pm 0.13)$ & $(0.00 \pm 0.13)$ & $0.22 \pm 0.11$ \\
$-v u_{y}$ & $0.23 \pm 0.12$ & $(0.01 \pm 0.13)$ & $0.25 \pm 0.12$ \\
$-w u_{z}$ & $0.23 \pm 0.13$ & $0.27 \pm 0.13$ & $0.21 \pm 0.11$ \\
$-\mathbf{U} \cdot \nabla u$ & $0.20 \pm 0.13$ & $0.22 \pm 0.13$ & $0.31 \pm 0.10$ \\
Residual & $(-0.03 \pm 0.17)$ & $0.36 \pm 0.14$ & $0.22 \pm 0.11$ \\
\hline
\end{tabular}

\section{a. Wind stress forcing}

The surface-layer zonal flow was to a large extent forced by the local winds (Figs. 5, 9, and 12, Tables 2 and 3). However, careful inspection of the surface momentum balance time series (Fig. 9) shows that direct wind-forced Yoshida jet dynamics (accelerations due exclusively to wind stress forcing) occurred primarily during the onset of wind bursts, before the wind stress had reached peak strength. This is also borne out in a lagged correlation analysis of the zonal wind stress and current accelerations (Fig. 13). Peak surface current accelerations occurred approximately 1 day prior to the peak wind stress.

\section{b. Zonal pressure gradient force}

The pressure gradient force was significantly correlated with the local tendency rate in all three layers (Figs. 9-12, Table 3). In particular, during the wellresolved period, there was a near balance between the pressure gradient force and local acceleration in the intermediate layer. Over the record length, the mean surface-layer pressure gradient force was large and westward, opposing the mean eastward wind stress. Indeed, wind stress and lagged pressure gradient force correlations computed over the well-resolved period (Fig. $13 \mathrm{c}$ ) indicate that approximately $8-10$ days after the peak wind stress, a pressure gradient force opposing the wind stress tended to form in the surface and intermediate layers. These pressure gradients generated by WWBs were the primary cause of westward accelerations in the intermediate layer (Fig. 10).

While there were many periods in which the magnitude of the dynamic height gradient increased monotonically from $500 \mathrm{~m}$ to the surface, there were also many periods in which the pressure gradient exhibits substantial vertical structure with middepth maxima (Fig. 6a). Note that a nonzero pressure gradient at the reference level (500 db) would bias the pressure gradient at all shallower depths, and therefore would shift the "zero" contour, without changing the vertical structure.
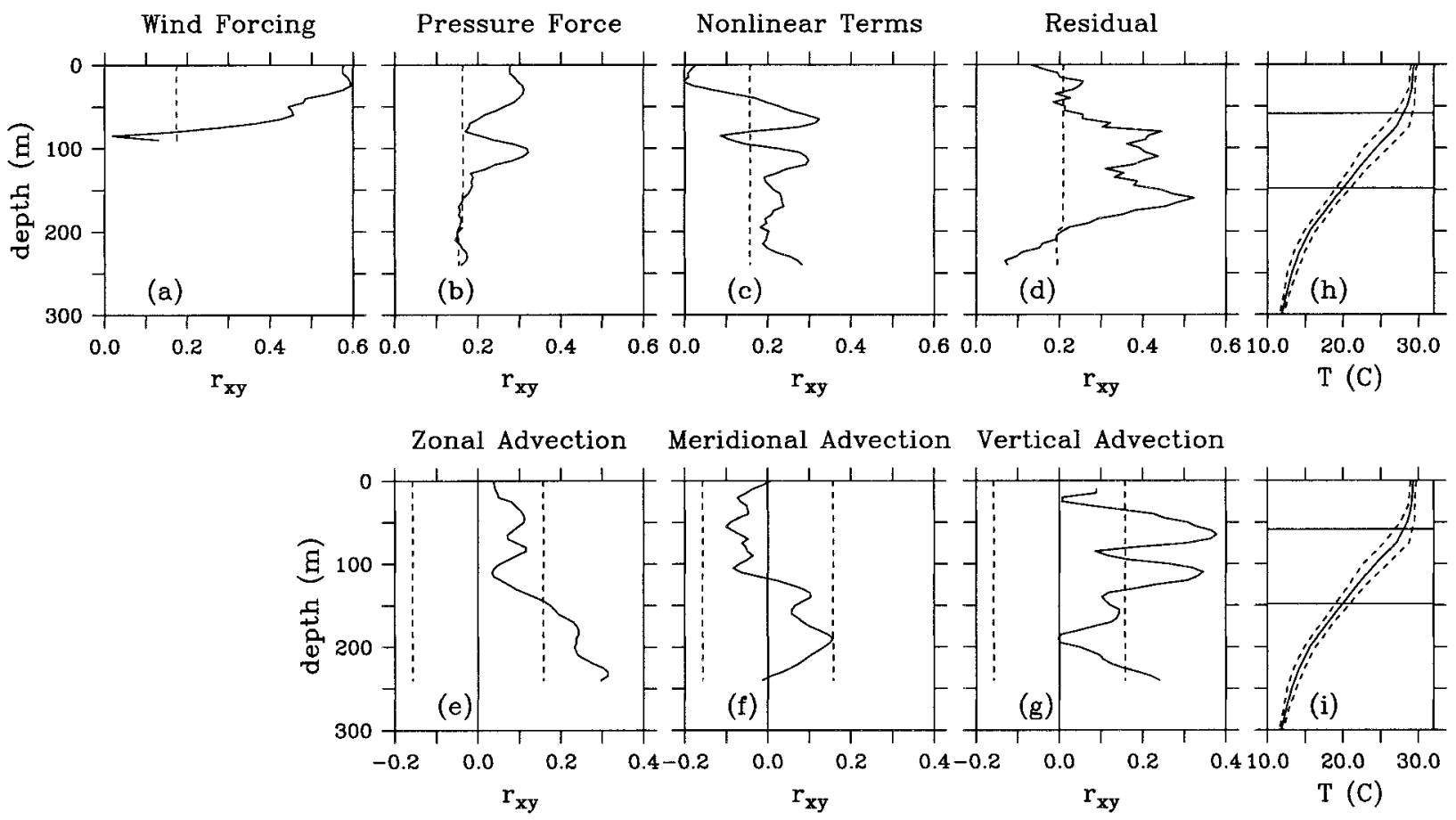

FIG. 12. Cross-correlations between the $0^{\circ}, 156^{\circ} \mathrm{E}$ depth-dependent local tendency rate and the (a) body force stress divergence (wind forcing), (b) zonal pressure gradient force, (c) nonlinear terms (net zonal, meridional, and vertical advection), (d) residual, (e) zonal advection, (f) meridional advection, and (g) vertical advection. (h) Mean temperature profile and its standard deviation envelope at $0^{\circ}$, $156^{\circ}$ E. (i) Same as (h). The two horizontal lines in (h) and (i) show the mean depths of the $28^{\circ} \mathrm{C}$ and $20^{\circ} \mathrm{C}$ isotherms, which define the surface, intermediate, and Equatorial Undercurrent layers. Correlations are computed over the entire record. The dashed lines in (a)-(g) represent the $90 \%$ significance levels. 


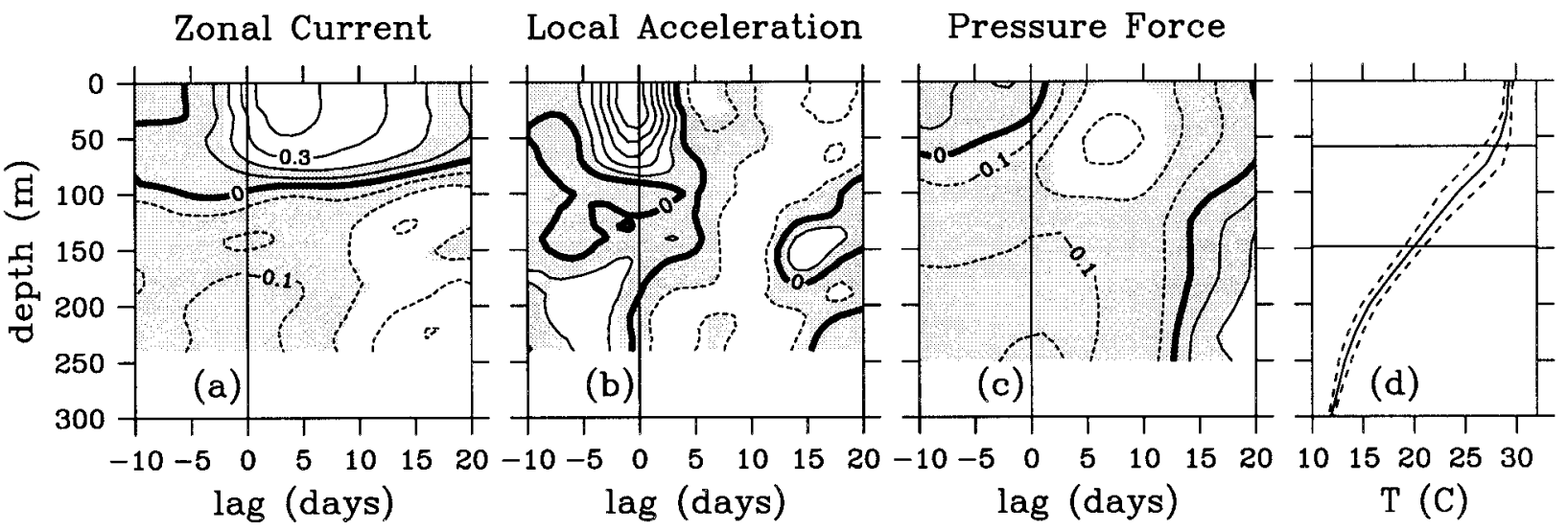

FIG. 13. Lagged correlation between local zonal wind stress and (a) zonal current, (b) local zonal current acceleration, and (c) zonal pressure gradient force as a function of depth at $0^{\circ}, 156^{\circ} \mathrm{E}$. A positive lag implies that wind stress variability occurs prior to the respective variable anomaly. (d) Mean temperature profile and its standard deviation envelope at $0^{\circ}, 156^{\circ} \mathrm{E}$. The two horizontal lines show the mean depths of the $28^{\circ} \mathrm{C}$ and $20^{\circ} \mathrm{C}$ isotherms, which define the surface, intermediate, and Equatorial Undercurrent layers. Correlations are computed over the entire record for (a) and (b), and over the period May 1992-April 1993 for (c). Correlations that are not significant at the 90\% confidence level are shaded. The CI is 0.1 .

\section{c. Nonlinearities}

Nonlinear terms are as much a result of local accelerations having occurred, as they are a cause of the accelerations. Therefore, correlations with the local tendency rate are not required for nonlinearity to be important in the balance. Nevertheless, meridional and vertical advection were significantly correlated with the tendency rate in the surface layer; vertical advection was significantly correlated in the intermediate layer; and zonal, meridional, and vertical advection were all significantly correlated with the local tendency rate in the EUC layer (Table 3). More importantly, zonal and vertical advection were large relative to the local acceleration, particularly in the intermediate and EUC layers (Fig. 7, Table 2).

Vertical shear associated with the reversing jets caused vertical advection to be largest at the depths of the current reversals (Fig. 7c). At the EUC-intermediate layer interface, vertical advection tended to be positive (inducing eastward accelerations) primarily due to upwelling, which brought eastward EUC flow into the intermediate layer. On the other hand, vertical advection at the intermediate-surface layer interface was at times positive and at other times negative due to a variety of vertical velocity and vertical shear combinations. Although some vertical advection events were associated with local Ekman upwelling and downwelling, the strong vertical advection in the EUC layer during AprilAugust 1992 was due to prolonged upwelling that cannot be explained by local Ekman dynamics. In fact, in marked contrast to the correlation analyses shown in Fig. 13, lagged correlations between local zonal wind stress and the nonlinear terms did not show significant correlation patterns and therefore are not shown.

One of the strongest nonlinear events was during July and August 1993, when zonal advection strengthened the eastward flowing EUC, and vertical advection upwelled the EUC into the intermediate layer. Together with eastward wind forcing in the surface layer, these nonlinearities were largely responsible for the anomalous eastward flow throughout the upper $240 \mathrm{~m}$ during the boreal summer of 1993. Similar but less extreme nonlinearities and anomalous eastward flow were also observed during the boreal summer of 1992 .

\section{d. The residual}

In principle, the residual (Fig. 8a) should be due to the stress divergence, which deviates from the wind body force. However, since the residual also includes the effects of the pressure gradient at $500 \mathrm{db}$ and the accumulation of computational and sampling errors, it cannot be interpreted unambiguously in terms of physical processes such as vertical mixing. Mixing in the surface layer is due to a combination of wind stirring, nighttime convection, and shear instability, while below the surface layer mixing is due primarily to shear instability. Since vertical mixing within the surface layer may enter both the wind body force term and the residual according to (3), we will focus on subsurface mixing. Shear instability is expected in regions of low Richardson number $\left[\mathrm{Ri}=N^{2} /\left(u_{z}^{2}+v_{z}^{2}\right)\right]$, that is, regions with very high shear $\left(u_{z}^{2}+v_{z}^{2}\right)$ and weak stratification $\left(N^{2} \sim-g \rho_{z} / \rho_{0}\right.$, where $g$ is gravity). The bulk Richardson number, shown in Fig. 8b, was estimated using the 5 -day filtered current and temperature time series. Note that our estimate of the bulk Richardson number is expected to be larger than an estimate based on high vertical resolution, temporally unfiltered data that would be required to quantify the effects of shear instability on individual mixing events. Qualitatively, however, we found low Richardson numbers predominately in the 
surface layer, with occasional low values also in the intermediate and EUC layers. Thus subsurface residuals may well be due in part to vertical mixing.

\section{Discussion and summary}

The western equatorial Pacific during the study period (March 1992 through April 1994) was characterized by weak trade winds punctuated by frequent westerly wind bursts. Consequently, the upper ocean was constantly readjusting to episodic wind stress forcing. Yoshida jet dynamics (accelerations due exclusively to wind stress forcing) were observed in the surface layer above the thermocline during the onset of wind bursts. Consequently, zonal currents lagged zonal wind stresses by about 3 days on average (Fig. 13a). However, typically within 8 days of the peak wind stress, a pressure gradient developed that partially compensated for the wind stress forcing (Fig. 13c). Pressure gradients generated by the wind bursts extended below the surface layer and caused accelerations in the upper thermocline in a direction opposing the wind forcing 8-11 days after the peak wind forcing (Fig. 13). The near balance between the pressure gradient force and the local acceleration in the intermediate layer (Fig. 10) suggests that these pressure gradients were due to equatorial waves. Furthermore, the complex vertical structure in the pressure gradient (Fig. 6a) suggests that high-order baroclinic modes may be important. Quantitative projection of the data onto meridional and vertical mode Kelvin and Rossby waves (e.g., Boulanger and Menkes 1995), however, is beyond the scope of this paper.

The importance of pressure gradients in the readjustment process is consistent with the results from the Richardson et al. (1999) model analysis. They found that baroclinic Rossby and Kelvin waves propagating from the edges, particularly the eastern edge, of the wind patch were primarily responsible for the subsurface westward currents near the eastern edge of the wind patch. Thus, in general, the time it takes for a wind compensating pressure gradient to develop at our study site depends on many factors, including the location of the site relative to the wind patch edges and the propagation speed of the baroclinic Kelvin and Rossby waves generated by the wind burst. For typical WWB fetches of $3000-4000 \mathrm{~km}$ and equatorial wave speeds of 1-3 $\mathrm{m} \mathrm{s}^{-1}$, adjustment within the forcing region would begin within approximately $8-12$ days. The 8 -day lag between the local wind stress and compensating pressure gradient (Fig. 13) that we found is roughly consistent with this range of expected adjustment times.

Our analysis shows that zonal winds drive slablike flows above the thermocline and indirectly drive countercurrents within the upper portion of the thermocline. Although our layer definitions were based on temperature, salinity stratification can have variability independent of the temperature stratification. In particular, the top of the halocline at times is found to be shallower than the top of the thermocline. The layer between these two surfaces is referred to as the "barrier layer" (Lukas and Lindstrom 1991; Ando and McPhaden 1997) since it inhibits the mixing of cold thermocline water into the surface layer. Just as the "warm pool" can be defined as the region with surface waters warmer than $28^{\circ} \mathrm{C}$, a "fresh pool" can be defined as the region with salinity less than 35 psu. Variability in the location of the fresh pool has been documented by Hénin et al. (1998), Delcroix and Picaut (1998), and Cronin and McPhaden (1998). The "fresh pool" and "warm pool" are not necessarily colocated. Roemmich et al. (1994) show that, if the pressure gradient due to a zonal salinity front within a deep isothermal mixed layer is large enough, it could induce a vertically sheared zonal current within the mixed layer, which could then tilt the zonal salinity front vertically to generate barrier layers. Our analysis shows that there are significant salinity-induced pressure gradients in the surface layer and at the depth of the salinity maximum in the intermediate and EUC layers (Figs. 6b and 11a). Using 14 years of hydrographic data, Kessler (1999) showed that the 150-200 m salinity maximum at $0^{\circ}, 165^{\circ} \mathrm{E}$ waxed and waned as the high salinity tongue was advected westward and equatorward from a ventilation region in the southeast Pacific. Our results indicate that this salinity advection has a dynamical effect on the Equatorial Undercurrent.

Reversing jets are due primarily to the interplay between wind forcing and compensating pressure gradients. Nevertheless, nonlinear terms (zonal, meridional, and vertical advection) are large (Figs. 7 and 9-11) and have significant correlations with the local acceleration. As discussed by Philander and Pacanowski (1981) and McCreary (1985), assuming the vertical velocity was due to meridional Ekman convergences and divergences and that the vertical shear took the sign of the wind forcing, one might expect that vertical advection would cause eastward accelerations regardless of the direction of the wind stress. That is, easterlies would tend to upwell the EUC and westerlies would tend to downwell wind-driven eastward surface flow. However, a simple relationship between wind stress and zonal shear does not appear to hold in the highly variable reversing jet regime found in the western equatorial Pacific. Likewise, vertical velocity appears to have large variability due to remote forcing, particularly in the EUC layer during the period April-August 1992. Consequently, at this location, vertical advection is significantly more complex than suggested by Philander and Pacanowski (1981) and McCreary (1985).

Zonal and vertical advection were very large during the boreal summers of 1992 and 1993, when the currents became anomalously eastward throughout the upper 240 $\mathrm{m}$. The record length is too short to determine whether these anomalies were isolated events, a feature of the annual cycle, or a manifestation of interannual variability. Both events were during the termination of El Niño conditions. We note, however, that at $0^{\circ}, 165^{\circ} \mathrm{E}$, 
a site which had over eight years of moored current meter data, anomalous eastward flow throughout the upper water column is evident in the annual mean June and July (Yu and McPhaden 1999). Yu and McPhaden reproduced much of this seasonal anomalous eastward flow using a forced linear analytical model. If the anomalous eastward flow observed at $0^{\circ}, 156^{\circ} \mathrm{E}$ was in fact a manifestation of the seasonal variability in the western equatorial Pacific, then the importance of nonlinearities in the seasonal cycle would need to be revisited.

Mixing was not directly measured in this analysis, and therefore its role in the dynamics of the current flow has not been highlighted. Nevertheless, mixing is expected to be important, particularly in the surface layer where wind stirring and nighttime convection occur, and at surface and subsurface depths of low Richardson number.

In summary, because of the unique dynamics found on the equator and the strong westerly wind bursts in the western equatorial Pacific, the upper-ocean currents in the western equatorial Pacific are highly variable, changing direction both with time and depth. Using data from the TOGA COARE enhanced monitoring array of TAO and ADCP moorings, nearly all terms in the upperocean zonal momentum balance have been evaluated at the central site $\left(0^{\circ}, 156^{\circ} \mathrm{E}\right)$ for up to two years. The analysis highlights the complex interplay of local and remote wind forcing, and the importance of pressure gradients and nonlinearities as the ocean adjusts to these variable winds of the western equatorial Pacific.

Acknowledgments. We gratefully acknowledge R. Lukas (UH) for providing the $0^{\circ}, 154^{\circ} \mathrm{E}$ and $0^{\circ}, 160.5^{\circ} \mathrm{E}$ SEACAT temperature and salinity data, and K. Kutsuwada (Tokai U.) for providing ADCP data at $0^{\circ}, 147^{\circ} \mathrm{E}$ and $0^{\circ}, 154^{\circ} \mathrm{E}$. R. Helber (USF) kindly provided his estimate of the vertical velocity and the gap-filled zonal currents at $0^{\circ}, 156^{\circ} \mathrm{E}$. D. McClurg (PMEL) assisted in the computation of the dynamic heights and the data availability plots. The authors thank J. Donovan (USF), R. Cole (USF), P. Freitag (PMEL), and the PMEL TAO Project Office for their hard work collecting and processing data. Helpful comments were provided by E. Lindstrom and R. Richardson. RHW was supported by NSF Grant OCE9525912. MFC and MJM were supported by NOAA's Office of Global Programs. This is PMEL contribution 1912.

\section{APPENDIX}

\section{Salinity Extrapolation}

Conductivity (from which salinity is computed) is not a standard measurement on TAO moorings. Thus for the computation of dynamic height at TAO thermistor moorings, typically salinity is estimated from temperature using a climatological temperature-salinity $(T-S)$ curve (e.g., from Levitus et al. 1994). However, during the COARE enhanced monitoring period, over 390 CTD casts were made within $100 \mathrm{~km}$ of the equator in the COARE domain and, in addition, several moorings had SEACAT temperature and conductivity sensors (Fig. 2b). While the CTDs had good vertical resolution, they were sparsely sampled in time. Likewise, while the moored SEACATs had good temporal resolution, they were sparsely sampled in the vertical. As described below, these CTD and moored temperature and salinity measurements were blended together using optimal interpolation to create time-dependent $T-S$ curves at each site along the equator between $0^{\circ}, 154^{\circ} \mathrm{E}$ and $0^{\circ}, 165^{\circ} \mathrm{E}$. These $T-S$ curves were then used to estimate salinity at the temperature measurement levels below the bottom SEACAT depth for computation of the dynamic height relative to $500 \mathrm{db}$.

As a first step, at each site, a slowly varying $T-S$ curve was estimated from CTD data. Typically, near deployments and recovery periods there were 2-20 CTDs and during the COARE IOP there were as many as 75 CTDs taken within a 3 -week period near the $0^{\circ}$, $156^{\circ} \mathrm{E}$ mooring. Thus, all CTDs falling within a $2^{\circ} \times$ $4^{\circ} \times 3$ week window centered at a mooring site were averaged on sigma surfaces. These approximately 6-monthly CTD $T-S$ curves were then interpolated in time to obtain a gridded time-dependent CTD $T-S$ curve for each site.

Then, to blend in the buoy SEACAT data, the SEACAT $T-S$ deviations from the CTD $T-S$ curve were computed for each day and were mapped onto a temperature grid from $5^{\circ}$ to $29^{\circ} \mathrm{C}$ using an optimal interpolation (OI) scheme (Bretherton et al. 1976). The temperature grid had $0.5^{\circ} \mathrm{C}$ resolution above $27^{\circ} \mathrm{C}$ and $1^{\circ} \mathrm{C}$ resolution below $27^{\circ} \mathrm{C}$. Optimal interpolation uses a prescribed correlation function to determine how to weight "neighboring" perturbation measurements. In our application, we used a Gaussian time- and temperaturelagged correlation function $C\left[\left(t_{i}-t_{j}\right),\left(T_{i}-T_{j}\right)\right]$ of the form:

$$
\begin{aligned}
& C\left[\left(t_{i}-t_{j}\right),\left(T_{i}-T_{j}\right)\right] \\
& \quad=\exp \left[-\left(\frac{t_{i}-t_{j}}{\lambda_{t}}\right)^{2}\right] \cdot \exp \left[-\left(\frac{T_{i}-T_{j}}{\lambda_{T}}\right)^{2}\right],
\end{aligned}
$$

where $t_{i}$ and $t_{j}$ are times of neighboring measurements, $T_{i}$ and $T_{j}$ are temperature values of neighboring measurements, and $\lambda_{T}$ and $\lambda_{t}$ are the correlation temperature and timescales. At zero lags, the autocorrelations were increased by a factor $1 / R_{0}$, where $R_{0}$ (set as 0.7 ) is equivalent to the fraction of true variance measured. The temporal correlation scale was set as 20 days. Because variations from the mean $T-S$ curve above the thermocline are expected to be somewhat independent of variations in and below the thermocline, the temperature correlation scale $\lambda_{T}$ was assumed to be of the form:

$$
\lambda_{T}(T)=\left(2^{\circ} \mathrm{C}\right) \tanh \left(\frac{26^{\circ} \mathrm{C}-T}{1^{\circ} \mathrm{C}}\right)+3^{\circ} \mathrm{C} .
$$


Thus, the temperature correlation scale is approximately $1^{\circ} \mathrm{C}$ above $27^{\circ} \mathrm{C}$, and approximately $5^{\circ} \mathrm{C}$ below $25^{\circ} \mathrm{C}$. Surface salinity measurements essentially have no impact on the deep $T-S$ variations; there, the $T-S$ curve reverts to the slowly varying CTD $T-S$ curve.

Finally, the OI-gridded $T-S$ variations were added to the slowly varying CTD $T-S$ curves to generate a time series of the $T-S$ curve for the full temperature range at each site along the equator. These $T-S$ curve time series were then used to determine salinity at thermistor depths below the bottom SEACAT sensor.

\section{REFERENCES}

Ando, K., and M. J. McPhaden, 1997: Variability of surface layer hydrography in the tropical Pacific Ocean. J. Geophys. Res., 102, $23063-23078$.

Boulanger, J.-P., and C. Menkes, 1995: Propagation and reflection of long equatorial waves in the Pacific Ocean during the 1992 1993 El Niño. J. Geophys. Res., 100, 25 041-25 059.

Bretherton, F. P., R. E. Davis, and C. B. Fandry, 1976: A technique for objective analysis and design of oceanographic experiments applied to MODE-73. Deep-Sea Res., 23, 559-582.

Cane, M. A., and E. S. Sarachik, 1976: Forced baroclinic ocean motions. I. The linear equatorial unbounded case. J. Mar. Res., 34, 629-665.

Cronin, M. F., and M. J. McPhaden, 1997: The upper ocean heat balance in the western equatorial Pacific warm pool during September-December 1992. J. Geophys. Res., 102, 8533-8553.

- , and - 1998: Upper ocean salinity balance in the western equatorial Pacific. J. Geophys. Res., 103, 27 567-27 587.

Delcroix, T., and J. Picaut, 1998: Zonal displacement of the western equatorial Pacific "fresh pool." J. Geophys. Res., 103, 10871098 .

_ - G. Eldin, M. McPhaden, and A. Morliere, 1993: Effects of westerly wind bursts upon the western equatorial Pacific Ocean, February-April 1991. J. Geophys. Res., 98, 16 379-16 385.

Eriksen, C. C., 1993: Equatorial ocean response to rapidly translating wind bursts. J. Phys. Oceanogr., 23, 1208-1230.

Fairall, C., E. F. Bradley, J. S. Godfrey, G. A. Wick, J. B. Edson, and G. S. Young, 1996a: Cool skin and warm layer effects on sea surface temperature. J. Geophys. Res., 101, 1295-1308

,-- D. P. Rogers, J. B. Edson, and G. S. Young, 1996b: Bulk parameterization of air-sea fluxes for Tropical Ocean Global Atmosphere Coupled Ocean-Atmosphere Response Experiment algorithm. J. Geophys. Res., 101, 3747-3764.

Firing, E., S. E. Wiffels, and P. Hacker, 1998: Equatorial subthermocline currents across the Pacific. J. Geophys. Res., 103, $21413-21414$.

Freitag, H. P., M. McCarty, C. Nosse, R. Lukas, M. J. McPhaden, and M. F. Cronin, 1999: COARE SEACAT data: Calibration and quality control procedures. NOAA Tech. Memo. ERL PMEL115, 89 pp. [Available from Pacific Marine Environmental Laboratory, 7600 Sand Point Way NE, Seattle, WA 98115.]

Giese, B. S., and D. E. Harrison, 1990: Aspects of the Kelvin wave response to episodic wind forcing. J. Geophys. Res., 95, 72897312.

Halpern, D., and H. P. Freitag, 1987: Vertical motion in the upper ocean of the equatorial eastern Pacific. Proc. Int. Symp. on Equatorial Vertical Motion, Oceanol. Acta SP, 19-26.

Harrison, D. E., and A. P. Craig, 1993: Ocean model studies of upperocean variability at $0^{\circ}, 160^{\circ} \mathrm{W}$ during the $1982-1983$ ENSO: Local and remotely forced response. J. Phys. Oceanogr., 23, 426-451.

- , and G. A. Vecchi, 1997: Westerly wind events in the tropical Pacific. 1986-95. J. Climate, 10, 3131-3156.

Helber, R. W., and R. H. Weisberg, 1998: Equatorial upwelling in the western Pacific warm pool. COARE98, Proc. Conf. on the TOGA Coupled Ocean-Atmosphere Response Experiment, Boulder, CO, WCRP-107, WMO/TD-No. 940

Hénin, C., Y. Du Penhoat, and M. Ioualalen, 1998: Observations of sea surface salinity in the western Pacific fresh pool: Large-scale changes in 1992-1995. J. Geophys. Res., 103, 7523-7536.

Hisard, P., J. Merle, and B. Voituriez, 1970: The equatorial undercurrent at $170^{\circ} \mathrm{E}$ in March and April 1967. J. Mar. Res., 28, 281-303.

Kessler, W. S., 1999: Interannual variability of the subsurface highsalinity tongue south of the equator at $165^{\circ} \mathrm{E}$. J. Phys. Oceanogr., 29, 2038-2049.

— M. J. McPhaden, and K. M. Weickmann, 1995: Forcing of intraseasonal Kelvin waves in the equatorial Pacific. J. Geophys. Res., 100, 10 613-10 631.

Kuroda, Y., and M. J. McPhaden, 1993: Variability in the western equatorial Pacific Ocean during Japanese Pacific Climate Study cruises in 1989 and 1990. J. Geophys. Res., 98, 4747-4759.

Levitus, S., and T. P. Boyer, 1994: World Ocean Atlas 1994. Vol. 4, Temperature, NOAA Atlas NESDIS 4, U.S. Dept. of Commerce, $117 \mathrm{pp}$.

_, R. Burge, and T. P. Boyer, 1994: World Ocean Atlas 1994. Vol. 3, Salinity, NOAA Atlas NESDIS 3, U.S. Dept. of Commerce, $99 \mathrm{pp}$.

Lukas, R., and E. Lindstrom, 1991: The mixed layer of the western equatorial Pacific Ocean. J. Geophys. Res., 96 (Suppl.), 33433357.

Madden, R. A., and P. R. Julian, 1994: Observations of the 40-50day tropical oscillation-A review. Mon. Wea. Rev., 122, 814837.

McCreary, J. P., Jr., 1985: Modeling equatorial ocean circulation. Annu. Rev. Fluid Mech., 17, 359-409.

— a moving wind field. J. Geophys. Res., 91, 11 691-11 705.

McPhaden, M. J., H. P. Freitag, S. P. Hayes, B. A. Taft, Z. Chen, and K. Wyrtki, 1988: The response of the equatorial Pacific Ocean to a westerly wind burst in May 1986. J. Geophys. Res., 93, $10589-10603$.

_ _ S. P. Hayes, L. J. Mangum, and J. M. Toole, 1990: Variability in the western equatorial Pacific Ocean during the 1986-87 El Niño-Southern Oscillation event. J. Phys. Oceanogr., 20, 190208.

—, F. Bahr, Y. Du Penhoat, E. Firing, S. P. Hayes, P. P. Niiler, P. L. Richardson, and J. M. Toole, 1992: The response of the western equatorial Pacific Ocean to westerly wind bursts during November 1989 to January 1990. J. Geophys. Res., 97, $14289-$ 14303.

_- and Coauthors, 1998: The Tropical Ocean Global Atmosphere (TOGA) observing system: A decade of progress. J. Geophys. Res., 103, 14 169-14 240.

Nakazawa, T., 1988: Tropical super clusters within intraseasonal variations over the western Pacific. J. Meteor. Soc. Japan, 66, 823830.

Philander, S. G. H., and R. C. Pacanowski, 1981: Response of the equatorial oceans to periodic forcing. J. Geophys. Res., 86, 1903-1916.

Plimpton, P. E., H. P. Freitag, and M. J. McPhaden, 1997: ADCP velocity errors from pelagic fish schooling around equatorial moorings. J. Atmos. Oceanic Technol., 14, 1212-1223.

Qiao, L., and R. H. Weisberg, 1997: The zonal momentum balance of the Equatorial Undercurrent in the central Pacific. J. Phys. Oceanogr., 27, 1094-1119.

Rebert, J., J. Donguy, G. Eldin, and K. Wyrtki, 1985: Relations between sea level, thermocline depth, heat content and dynamic height in the tropical Pacific. J. Geophys. Res., 90, 1171911725.

Richardson, R. A., I. Ginis, and L. M. Rothstein, 1999: A numerical investigation of the local ocean response to westerly wind burst forcing in the western equatorial Pacific. J. Phys. Oceanogr., 29, $1334-1352$. 
Roemmich, D., M. Morris, W. R. Young, and J. R. Donguy, 1994: Fresh equatorial jets. J. Phys. Oceanogr., 24, 540-558.

Smyth, W. D., D. Hebert, and J. N. Moum, 1996: Local ocean response to a multiphase westerly windburst. Part 1 . Dynamic response. J. Geophys. Res., 101, 22 495-22 512.

Stommel, H., 1960: Wind-drift near the equator. Deep-Sea Res., 6 , 298-302.

Tang, T. Y., and R. H. Weisberg, 1984: On the equatorial Pacific response to the 1982/1983 El Niño-Southern Oscillation event. J. Mar. Res., 42, 809-829.

Weingartner, T. J., and R. H. Weisberg, 1991: On the annual cycle of equatorial upwelling in the central Atlantic Ocean. J. Phys. Oceanogr., 21, 68-82.

Weisberg, R. H., and T. Y. Tang, 1983: Equatorial ocean response to growing and moving wind systems with application to the Atlantic. J. Mar. Res., 41, 461-486.

— and - 1987: Further studies on the response of the equatorial thermocline in the Atlantic Ocean to the seasonally varying trade winds. J. Geophys. Res., 92, 3709-3727.
- , and $-1990:$ A linear analysis of equatorial Atlantic Ocean thermocline variability. J. Phys. Oceanogr., 20, 1813-1825.

— , and S. P. Hayes, 1995: Upper ocean variability on the equator in the Pacific at $170^{\circ}$ W. J. Geophys. Res., 100, $20485-20498$.

— and C. Wang, 1997: Slow variability in the equatorial westcentral Pacific in relation to ENSO. J. Climate, 10, 1998-2017.

- , and L. Qiao, 2000: Equatorial upwelling in the central equatorial Pacific estimated from moored velocity profilers. J. Phys. Oceanogr., 30, 105-124.

Wyrtki, K., 1981: An estimate of equatorial upwelling in the Pacific. J. Phys. Oceanogr., 11, 1205-1214.

Yoshida, K., 1959: A theory of the Cromwell Current and equatorial upwelling. J. Oceanogr. Soc. Japan, 15, 154-170.

Yu, X., and M. J. McPhaden, 1999: Seasonal variability in the equatorial Pacific. J. Phys. Oceanogr., 29, 925-947.

Zhang, K. Q., and L. M. Rothstein, 1998: Modeling the oceanic response to westerly wind bursts in the western equatorial $\mathrm{Pa}$ cific. J. Phys. Oceanogr., 28, 2227-2249. 